Check for updates

Cite this: RSC Adv., 2017, 7, 33789

\title{
Advances in electrode materials for Li-based rechargeable batteries
}

\author{
Hui Zhang, ${ }^{a}$ Chengyu Mao, (D) b Jianlin Li (D) ${ }^{\text {bc }}$ and Ruiyong Chen (D)*de
}

Rechargeable lithium-ion batteries store energy as chemical energy in electrode materials during charge and can convert the chemical energy into electrical energy when needed. Tremendous attention has been paid to screen electroactive materials, to evaluate their structural integrity and cycling reversibility, and to improve the performance of electrode materials. This review discusses recent advances in performance enhancement of both anode and cathode through nanoengineering active materials and applying surface coatings, in order to effectively deal with the challenges such as large volume variation, instable interface, limited cyclability and rate capability. We also introduce and discuss briefly the diversity and new tendencies in finding alternative lithium storage materials, safe operation enabled in aqueous electrolytes, and configuring novel symmetric electrodes and lithium-based flow batteries.

Received 18th April 2017 Accepted 27th June 2017

DOI: 10.1039/c7ra04370h

rsc.li/rsc-advances revolution of our modern society. Broad applications, ranging from portable electronics, power tools to electric vehicles and stationary energy storage, have been achieved. Intensive technological development has been realized through the enrichment in knowledge of electrode materials, electrolyte chemistry, storage mechanisms (such as intercalation chemistry, conversion reactions, lithium storage based on cleavage/formation of covalent bonds in $\mathrm{Li}-\mathrm{O}_{2}$ and $\mathrm{Li}-\mathrm{S}$ batteries), design and fabrication of nanostructured materials and coatings.

The materials chemistry related to the $\mathrm{Li}^{+}$intercalation phenomena was first discovered in the late 1970s. ${ }^{1}$ Classic LIBs store energy by shuttling $\mathrm{Li}^{+}$between the two electrodes through a rocking chair mechanism. ${ }^{2,3}$ Selections of electrode materials, electrolyte salts and solvents, binders, current collectors and

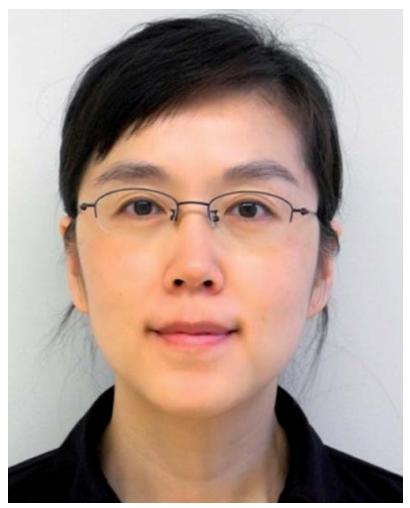

Hui Zhang has been an associate professor since 2015 at Qian Xuesen Laboratory of Space Technology, China Academy of Space Technology (CAST), Beijing, China. She received her Ph.D. in the Department of Materials Science and Engineering at Beijing University of Aeronautics and Astronautics (BUAA, China) in 2009. During 2009 to 2015, she had worked as postdoctoral fellow and then research assistant professor at West Virginia University (WVU), Morgantown, USA. Her recent research interests have focused on all solid state lithium ion batteries, advanced materials for energy storage and conversion, and surface \& interface science, etc.

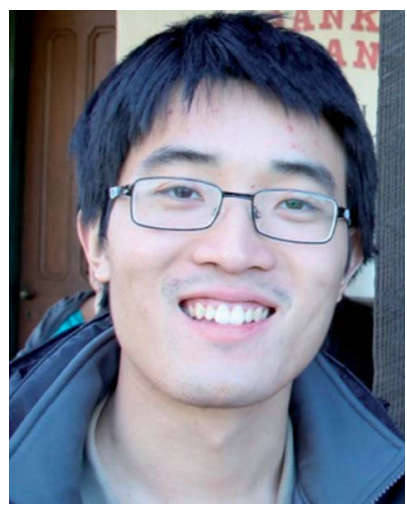

Chengyu Mao received his $B S$ and $P h D$ degrees in Materials Science and Engineering from Tsinghua University (2011) and University of California, Riverside (2016) respectively. $\mathrm{He}$ is currently a Postdoctoral Researcher at Oak Ridge National Laboratory. His current research involves cathode materials for Lithiumion batteries. 
separators have been recently reviewed by Blomgren. ${ }^{4}$ Current LIBs market is still dominated by those inorganic cathode materials (such as layered oxides, spinels and polyanion-type olivines) developed several decades ago. ${ }^{5}$ Great efforts have been devoted to reduce the cost and boost the performance of existing electrode materials. Our modern LIBs can hold more than twice as much as gravimetric energy density as those commercialized by Sony in 1991 and are ten time cheaper. ${ }^{6}$ However, the critical performance factors for LIBs such as accessible capacity, energy density, power density and service life need to be further improved to facilitate their market penetration. For instance, the driving range of electric vehicles powered by LIBs today is still unsatisfying. ${ }^{7}$

The specific capacity of electrode materials depends on the number of electrons that can be transferred per unit weight of the active materials. Numerous efforts have been made in the attempt to enhance the reversible capacity, including the development of multi-electron reaction materials, ${ }^{8-15}$ and novel battery systems such as new generations of $\mathrm{Li}-\mathrm{S}, \mathrm{Li}-\mathrm{air}$ batteries. ${ }^{16}$ Recently, oxygen anion redox reaction has been recognized in electrode materials, leading to an increase in the reversible capacity. ${ }^{\mathbf{1 7}}$ Compared to those classic insertion-type cathode and anode materials (mostly graphite-based), high capacity electrode materials are in general facing issues such as large volume change, insufficient coulombic efficiency (CE) and instable solid electrolyte interphase (SEI), leading to low rate capability, large polarization and limited cycle life.

Nanostructured electrodes have advantages such as reduced electron/ $/ \mathrm{Li}^{+}$diffusion length, and can improve the structural stability, and stabilize the SEI through preventing the build-up of internal stresses. ${ }^{18}$ In addition, nanosized particles also exhibit unique $\mathrm{Li}^{+}$storage mechanisms. ${ }^{19-21}$ The present paper provides an overview for the recent developments of high capacity anode and cathode materials for Li-based rechargeable

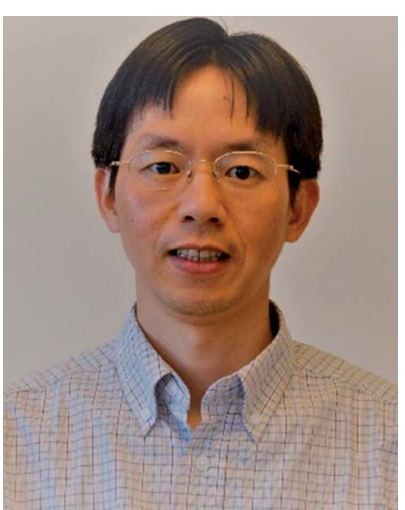

Jianlin Li is a staff scientist at Oak Ridge National Laboratory and an adjunct faculty at University of Tennessee. He received his $B S$ and $M S$ degrees from University of Science and Technology of China and Ph.D degree from University of Florida. All are in Materials Science and Engineering. His research interests span a wide range of areas including material synthesis, characterization and processing, slurry formulation, electrode engineering, nondestructive evaluation, and roll-to-roll manufacturing for energy storage and conversion application. He has won numerous prestigious awards, including two R\&D 100 awards. batteries through nanoengineering (Section 2), and significant performance improvement by applying nanostructured surface coatings (Section 3).

To obtain low-cost applications, safe operation and flexible systems, in Section 4, we discuss new trends in using metal-free electrode materials, novel electrolyte chemistry and new battery concepts and cell configurations for Li-based rechargeable batteries.

\section{Nanostructured electrode materials}

Due to the intrinsic low diffusivity of $\mathrm{Li}^{+}$in solid state materials, the lithiation rate is seriously limited in bulky materials. ${ }^{22,23}$ In contrast, nanomaterials, ${ }^{24}$ which have reduced dimensions and thus short $\mathrm{Li}^{+}$transportation distances, enable high reaction rates as well as fast electron transfer rates, and can boost the power of LIBs. Moreover, nanomaterials with high surface areas allow a high $\mathrm{Li}^{+}$flux across the electrode/electrolyte interface. Modification on chemical potential for $\mathrm{Li}^{+}$and $\mathrm{e}^{-}$for nanosized materials could also change the thermodynamics of electrode reactions and shift the electrode potential. However, nanosized materials inherit some drawbacks, such as low tap density, high reactivity towards the liquid medium during slurry preparation, and possible parasitic reactions with electrolytes. ${ }^{25}$ This section focuses on recent advances and discusses bottlenecks in the applications of nanomaterials for Li-based rechargeable batteries, organized as: (2.1) Si-based anodes; (2.2) carbonbased anodes; (2.3) lithium transition metal oxide-based cathodes; and (2.4) nanostructures in $\mathrm{Li}-\mathrm{S}$ batteries.

\subsection{Si-based anodes}

While several lithium transition metal oxide-based or polyanionic materials ${ }^{26}$ have been used as active cathode materials,

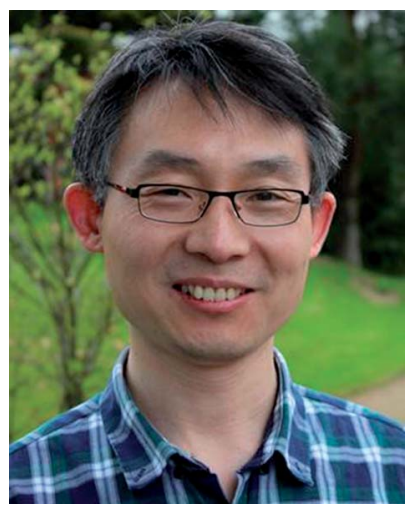

Ruiyong Chen is currently a Habilitand at Saarland University, Saarbrücken, Germany. He received his Ph.D. degree (summa cum laude) in 2011 from Saarland University under supervision of Prof. Rolf Hempelmann. Later on, he did his post-doctoral research at Karlsruhe Institute of Technology, Karlsruhe, Germany, holding research positions at different institutes (Institute of Nanotechnology, Institute for Applied Materials - Energy Storage Systems, Helmholtz Institute Ulm for Electrochemical Energy Storage), where he developed new intercalation cathode materials for lithium-ion batteries. In 2015, he joined the Korean Institute of Science and Technology (KIST) Europe in Saarbrücken as a senior scientist, leading efforts to develop new electrolytes for flow batteries and became project leader in 2016. 
graphite is the only commonly used active materials on anode side. However, graphite only allows one reversible $\mathrm{Li}^{+}$intercalation per six carbon atoms with a stoichiometry of $\mathrm{LiC}_{6}$, leading to a limited theoretical capacity of $372 \mathrm{~mA} \mathrm{~h} \mathrm{~g}^{-1}$ (or $975 \mathrm{~mA} \mathrm{~h}$ $\left.\mathrm{cm}^{-3}\right)$. In order to increase the energy density to $250 \mathrm{~W} \mathrm{~h} \mathrm{~kg}_{\text {cell }}{ }^{-1}$ and reduce the cost below $\$ 125 \mathrm{~kW} \mathrm{~h}^{-1}$, several elements in Table 1 have been examined and proved feasible to react with lithium in conventional organic electrolytes, according to alloy/ de-alloy mechanism $\left(\mathrm{Li}_{3.75} \mathrm{Si}, \mathrm{Li}_{3.75} \mathrm{Ge}\right.$, and $\mathrm{Li}_{4.25} \mathrm{Sn}$ as final products for $\mathrm{Si}, \mathrm{Ge}$ and $\mathrm{Sn}$, respectively). ${ }^{27}$ Considering the high capacity, abundant resource, low cost and non-toxicity, Si has received most attention in recent years. Owing to the formation of intermetallic Li-Si binary alloy (from $\mathrm{Li}_{12} \mathrm{Si}_{7}, \mathrm{Li}_{7} \mathrm{Si}_{3}$ to $\mathrm{Li}_{13} \mathrm{Si}_{4}$ ), Si can deliver almost the highest gravimetric and volumetric capacity among all anode candidates with a discharging

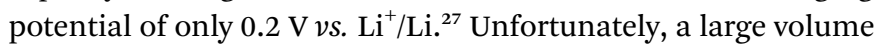
change up to $380 \%$ accompanying the alloy formation during cycling can lead to rapid and severely deterioration of electrode (such as cracks and pulverization). As a result, active materials lose contact with the current collector after a few cycles. Moreover, the significant volume change also breaks down SEI layers, exposing fresh Si surface to the electrolytes again. Continuous formation of new SEI layer consumes electrolytes and causes increase in polarization, which becomes another main issue for Si anode failure. ${ }^{28,29}$

Reducing Si particles into nanoscale, the large stress and strains associated with the volume change can be accommodated by the available voids, which can deliver superior electrochemical performance over the bulk counterparts. Early study has shown that a mixture of nanoscale $(78 \mathrm{~nm})$ Si powder and carbon black can exhibit a reversible capacity of $1700 \mathrm{~mA} \mathrm{~h}$ $\mathrm{g}^{-1} \cdot{ }^{30}$ Further work indicated a high reversible capacity of 3380 $\mathrm{mA} \mathrm{h} \mathrm{g}{ }^{-1}$ and $81 \%$ capacity retention after 40 cycles when the particle size was further reduced to $10 \mathrm{~nm}$ (Fig. 1a). ${ }^{31} \mathrm{~A} 250 \mathrm{~nm}$ thick Si film demonstrated a reversible capacity of $3800 \mathrm{~mA} \mathrm{~h}$ $\mathrm{g}^{-1}$ for 29 cycles with a fade of $0.09 \%$ per cycle at a $\mathrm{C} / 2.5$ rate. ${ }^{32}$ However, such structures tend to undergo pulverization during cycling, and to lose contact with current collector. Delamination and $\mathrm{Si}$ isolation can be clearly observed on cycled Si film anodes (Fig. 1b). ${ }^{33}$

Si nanowires/nanotubes as anode have some advantages. Firstly, the small geometry allows better accommodation of the volume changes (Fig. 1c and d). ${ }^{34}$ Secondly, a direct contact between each wire/tube and current collector enables efficient

Table 1 Theoretical capacity of some anode material candidates ${ }^{27}$

\begin{tabular}{lll}
\hline Element & $\begin{array}{l}\text { Gravimetric capacity/ } \\
\mathrm{mA} \mathrm{h} \mathrm{g}^{-1}\end{array}$ & $\begin{array}{l}\text { Volumetric capacity/ } \\
\mathrm{mA} \mathrm{h} \mathrm{cm}\end{array}$ \\
\hline $\mathrm{Si}$ & 3579 & 2190 \\
$\mathrm{Sn}$ & 960 & 1991 \\
$\mathrm{Al}$ & 993 & 1383 \\
$\mathrm{~Pb}$ & 549 & 1790 \\
$\mathrm{Ge}$ & 1384 & 2180 \\
$\mathrm{Sb}$ & 660 & 1889 \\
$\mathrm{P}$ & 2600 & 2250
\end{tabular}

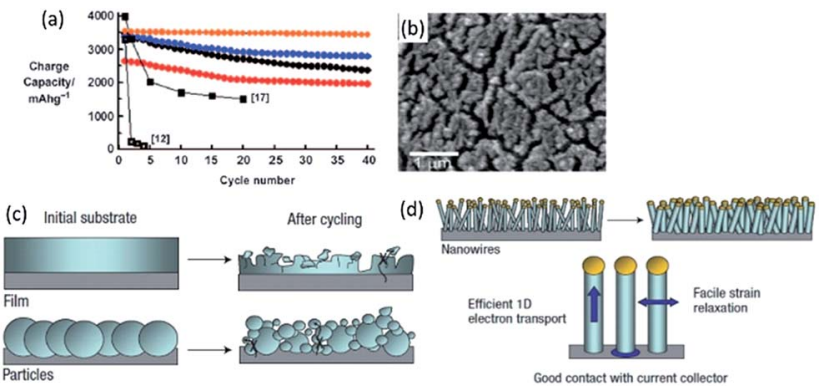

Fig. 1 (a) Charge capacity versus cycle number for Si powder with different sizes (red: $5 \mathrm{~nm}$, blue: $10 \mathrm{~nm}$, orange: $10 \mathrm{~nm}$ after carbon coating, black circles: $20 \mathrm{~nm}$ ). Reproduced with permission from ref. 31, copyright 2010, John Wiley and Sons. (b) SEM image of Si film cycled at C/3 for 40 cycles. Reproduced with permission from ref. 33, copyright 2010, American Chemical Society. (c, d) Schematics of morphological changes of Si over cycling. Reproduced with permission from ref. 34, copyright 2008, Nature Publishing Group.

charge transportation. Thirdly, the diffusion distance of $\mathrm{Li}^{+}$is reduced. Nanowires, grown directly on stainless steel current collectors using the vapor-liquid-solid or vapor liquid template-free methods, demonstrated a high capacity of 4277 $\mathrm{mA} \mathrm{h} \mathrm{g}{ }^{-1}$ during the first charge. It also showed good rate performance (2100 $\mathrm{mA} \mathrm{h} \mathrm{g}^{-1}$ at 1C) and good cyclability (3500 $\mathrm{mA} \mathrm{h}^{-1}$ for 20 cycles at $\mathrm{C} / 5$ ). Si nanotubes delivered $2600 \mathrm{~mA} \mathrm{~h}$ $\mathrm{g}^{-1}$ and $2100 \mathrm{~mA} \mathrm{~h} \mathrm{~g}{ }^{-1}$ at $\mathrm{C} / 20$ and $\mathrm{C} / 5$ rate over 50 cycles, respectively. ${ }^{35}$ Furthermore, anisotropic expansion (smaller axial expansion, but larger radial expansion) was observed for $\mathrm{Si}$ nanotubes.

Embedding $\mathrm{Si}$ in a matrix that can buffer the volume expansion has been widely explored. ${ }^{36}$ Chan et $a l .{ }^{37}$ uses the pyrolysis of sugar to coat carbon on Si nanowires. With additional carbon nanotubes as additive, the anode can remain a capacity of $1500 \mathrm{~mA} \mathrm{~h} \mathrm{~g}^{-1}$ over 75 cycles whereas the uncoated Si nanowires faded rapidly to $151 \mathrm{~mA} \mathrm{~h} \mathrm{~g}^{-1}$. Similarly, carbon coating has been utilized to stabilize the $\mathrm{Si}$ nanotubes/ electrolyte interface and to promote formation of stable SEI. ${ }^{38}$ A reversible capacity of $3200 \mathrm{~mA} \mathrm{~h} \mathrm{~g}{ }^{-1}$ and $89 \%$ capacity retention after 200 cycles at $1 \mathrm{C}$ was obtained in a full cell, using a $\mathrm{LiCoO}_{2}$ cathode. A rigid but ion-permeable $\mathrm{SiO}_{2}$, coated on the outer surface of Si nanotube (Fig. 2a), ${ }^{39}$ acts as a mechanical constraining layer to prevent the volume expansion, and thus can build up a thin and stable SEI layer. Such material demonstrated $88 \%$ capacity retention after 6000 cycles. Alternative to two-dimensional (2D) nanomaterials, mesoporous $\mathrm{Si}$ and other nanostructured $\mathrm{Si}$, which can be produced in large scale and quantity, have emerged to address the issues of volume expansion. Yushin et al..$^{40}$ used a hierarchical bottom-up approach to assemble Si spheres less than $30 \mathrm{~nm}$ on annealed carbon black substrates (Fig. 2b). Reversible capacity (1590 $\mathrm{mA} \mathrm{h} \mathrm{g}{ }^{-1}$ ) of five times higher than that of the graphite anode and stable cycling were observed.

Interconnected Si hollow nanospheres, capable of accommodating large strain without pulverization, delivered a high initial discharge capacity of $2725 \mathrm{~mA} \mathrm{~h} \mathrm{~g}^{-1}$ and maintained $1420 \mathrm{~mA} \mathrm{~h} \mathrm{~g}{ }^{-1}$ even after 700 cycles. ${ }^{41}$ Ma et al. ${ }^{42}$ reported nest- 
(a)
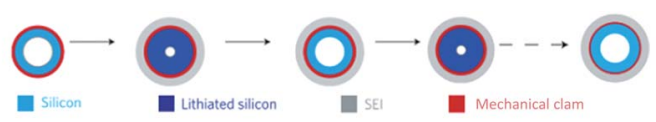

(b)

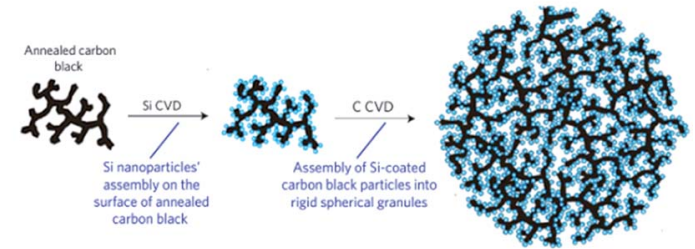

(c)

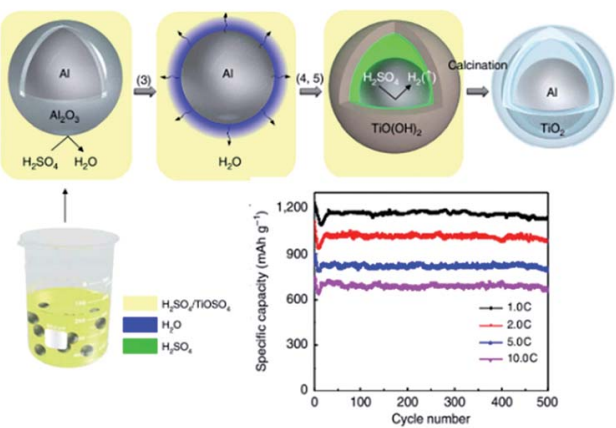

Fig. 2 (a) Designing a mechanical constraining layer on the hollow $\mathrm{Si}$ nanotubes can enable the formation of a thin and stable SEl. Reproduced with permission from ref. 39, copyright 2012, Nature Publishing Group. (b) Schematic of $\mathrm{Si}-\mathrm{C}$ nanocomposite granule formation through hierarchical bottom-up assembly. Reproduced with permission from ref. 40, copyright 2010, Nature Publishing Group. (c) Synthesis of $\mathrm{AlOTiO}$ and its half-cell performance. ${ }^{46}$

like Si nanospheres, prepared by a solvothermal method, with a first charge capacity of $3952 \mathrm{~mA} \mathrm{~h} \mathrm{~g}{ }^{-1}$ and a fast capacity loss (only $36 \%$ capacity retention after 50 cycles at $\mathrm{C} / 2$ ). 3D porous bulk Si particles with a $40 \mathrm{~nm}$ thin pore wall to accommodate large strains can maintain a discharge capacity of $2800 \mathrm{~mA} \mathrm{~h}$ $\mathrm{g}^{-1}$ at $1 \mathrm{C}$ even after 1000 cycles. ${ }^{43}$ Monodisperse hollow porous Si nanoparticles $(c a .120 \mathrm{~nm}),{ }^{44}$ formed by a template method and magnesiothermic reduction followed by $\mathrm{Ag}$ coating, showed a high specific capacity ( $3762 \mathrm{~mA} \mathrm{~h} \mathrm{~g}^{-1}$ ), long life time ( $99 \%$ retention after 99 cycles) and good rate performance (2000 $\mathrm{mA} \mathrm{h} \mathrm{g}{ }^{-1}$ at $\left.4 \mathrm{Ag}^{-1}\right)$. Well-designed mesoporous Si with tunable porosity also exhibited a reversible capacity of $2111 \mathrm{~mA} \mathrm{~h} \mathrm{~g}^{-1}$ at $\mathrm{C} / 5$ and a promising stability over 50 cycles. ${ }^{45} \mathrm{Al} / \mathrm{TiO}_{2}$ yolk-shell nanoparticles with adjustable interspace were made recently by a one-pot synthesis route, ${ }^{46}$ which demonstrated significant improvement in capacity $\left(1200 \mathrm{~mA} \mathrm{~h} \mathrm{~g}{ }^{-1}\right)$ and cycle life (average CE of $\sim 99.2 \%$ over 500 cycles at $1 \mathrm{C}$, and $661 \mathrm{~mA} \mathrm{~h} \mathrm{~g}^{-1}$ remained after 500 cycles at 10C (Fig. 2c)).

Si-based intermetallic compounds, including $\mathrm{Mg}_{2} \mathrm{Si}, \mathrm{CaSi}_{2}$, $\mathrm{SiO}, \mathrm{SiO}_{2}$ and $\mathrm{SiP}_{2},{ }^{47-49}$ have attracted intensive interest as promising anodes as well. For example, $\mathrm{Mg}_{2} \mathrm{Si}$ can deliver a large initial capacity of $1370 \mathrm{~mA} \mathrm{~h} \mathrm{~g}{ }^{-1}$. A hydrogen-driven chemical reaction was used to produce hexagonal $\mathrm{Li}_{2} \mathrm{MgSi}$ anode material, ${ }^{50}$ which showed a discharge capacity $828 \mathrm{~mA} \mathrm{~h}$ $\mathrm{g}^{-1}$ after ball-milling. The capacity retention was $50 \%$ after 100 cycles. Park et al. ${ }^{49}$ reported a nanostructured $\mathrm{SiP}_{2} / \mathrm{C}$ composite. Lithiation of $\mathrm{SiP}_{2}$ proceeds through a topotactic transition, amorphization and conversion, leading to $\mathrm{Li}_{13} \mathrm{Si}_{4}$ and $\mathrm{Li}_{3} \mathrm{P}$. A recombination reaction occurs upon delithiation. By controlling the cutoff voltage, high initial discharge and charge capacities of 1317 and $1137 \mathrm{~mA} \mathrm{~h} \mathrm{~g}{ }^{-1}$, respectively, were observed. After 100 cycles, the composite still delivered a high

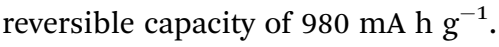

\subsection{Carbon-based anodes}

Due to the abundance, thermal and chemical stability, good electronic conductivity, low cost and good reversibility, ${ }^{27}$ carbon materials still play an important role as anode materials. Nanosized carbon materials have features such as porous nature, reduction in diffusion distance, and increased number of storage sites for $\mathrm{Li}^{+},{ }^{51}$ which enable higher capacity. A series of nanoporous hard carbons have been prepared by Tang et al. ${ }^{52}$ The obtained hierarchical porous carbons exhibited a maximum capacity of $503 \mathrm{~mA} \mathrm{~h} \mathrm{~g}{ }^{-1}$ at $\mathrm{C} / 5$ and still delivered $332.8 \mathrm{~mA} \mathrm{~h} \mathrm{~g}^{-1}$ at 5C. Similarly, carbon nanorings with $20 \mathrm{~nm}$ outer diameters and $3.5 \mathrm{~nm}$ thick wall (Fig. 3) demonstrated a reversible capacity of $1200 \mathrm{~mA} \mathrm{~h} \mathrm{~g}{ }^{-1}$ over 100 cycles at $0.4 \mathrm{~A}$ $\mathrm{g}^{-1} \cdot{ }^{53}$ When increasing current density to $45 \mathrm{~A} \mathrm{~g}^{-1}$, the capacity dropped to $500 \mathrm{~mA} \mathrm{~h} \mathrm{~g}{ }^{-1}$. Recently, Goodenough et al. ${ }^{54}$ produced a modified carbon by chemical introduction of ordered expanded nanographites and carbon microspheres with improved carbon interlayers alignment and $\mathrm{H}$ content. A high reversible capacity of $1180 \mathrm{~mA} \mathrm{~h} \mathrm{~g}^{-1}$ was preserved after 200 cycles at $0.1 \mathrm{~A} \mathrm{~g}^{-1}$ and it retained at $401 \mathrm{~mA} \mathrm{~h} \mathrm{~g}^{-1}$ after 1000 cycles even at $1 \mathrm{~A} \mathrm{~g}^{-1}$.

Since the discovery in $1991,{ }^{55}$ single wall carbon nanotubes (SWCNTs) and multiple wall carbon nanotubes (MWCNTs) have been extensively investigated as both active anode materials and as additives. Ab initio studies showed such nanotube systems could substantially improve the capacity by utilizing both nanotube exteriors and interiors. ${ }^{56}$ Insertion and extraction

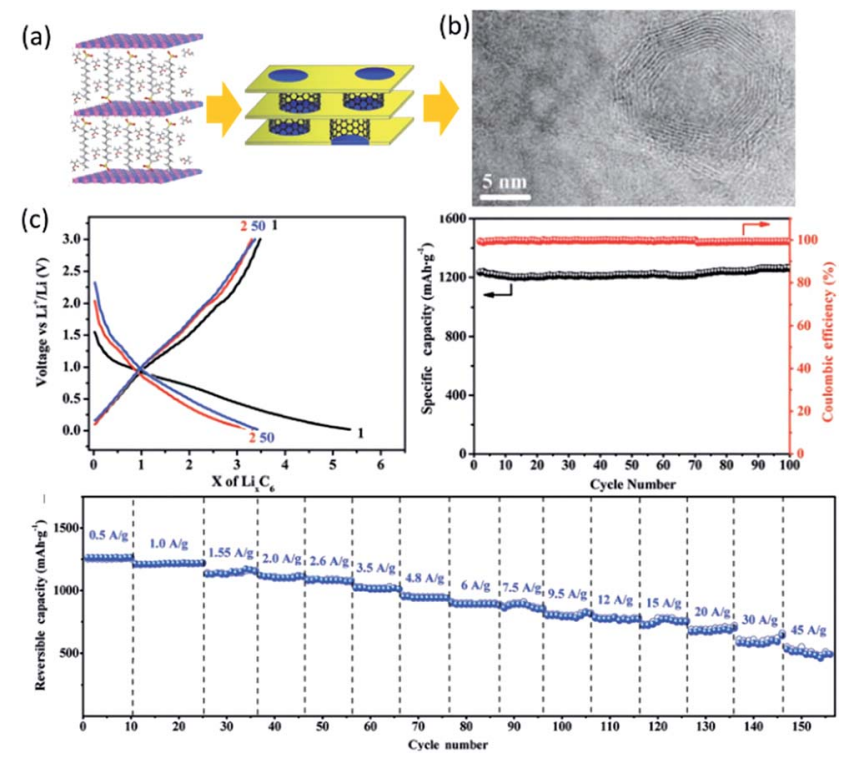

Fig. 3 (a) Catalytic growth of carbon nanorings. (b) TEM image. (c) Cycling performance of the carbon nanorings. Reproduced with permission from ref. 53, copyright 2012, John Wiley and Sons. 
capacities of $650 \mathrm{~mA} \mathrm{~h} \mathrm{~g}^{-1}$ have been achieved in coin cells using SWCNTs. ${ }^{57}$ Drilled MWCNTs with large quantity of functional groups by using $\mathrm{CoO}_{x}$ as the oxidation catalyst showed a high capacity of $625 \mathrm{~mA} \mathrm{~h} \mathrm{~g}^{-1}$, long life time and high CE. ${ }^{58}$ Due to their outstanding flexibility, high tensile strength and good conductivity, a robust 3D composite network architecture can be built by incorporating CNTs with other active materials. Synergistic effects of cylindrical 3D nanostructured $\mathrm{MoS}_{2}$ directly grown on CNTs kept the porosity to $\mathrm{Li}^{+}$, prevented $\mathrm{MoS}_{2}$ aggregation and utilized high conductive CNTs. ${ }^{5}$ High specific capacity, excellent cycling property, and good rate capability were observed. Electrochemically prelithiated $\mathrm{Fe}_{2} \mathrm{O}_{3}$ nanoparticles confined in CNTs demonstrated the highest reversible capacity (2071 $\mathrm{mA} \mathrm{h} \mathrm{g}^{-1}$ ) ever reported for a $\mathrm{Fe}_{2} \mathrm{O}_{3}$ anode. ${ }^{60}$ The significantly improved $\mathrm{Li}^{+}$storage was ascribed to the interfacial $\mathrm{Li}^{+}$ storage originating from the nanoconfinement of $\mathrm{CNTs}$. $\mathrm{TiO}_{2}{ }^{61}$ $\mathrm{Co}_{3} \mathrm{O}_{4},{ }^{62}$ and $\mathrm{NiO}^{63}$ fabricated with CNTs were all reported to have a superior electrochemical performance towards $\mathrm{Li}^{+}$storage. ${ }^{51}$

Thin graphene sheet with $\mathrm{sp}^{2}$-bonded carbon exhibits extraordinary electronic, mechanical and thermal properties. Experimental data showed that graphene itself can have a high reversible capacity of about 794-1054 $\mathrm{mA} \mathrm{h} \mathrm{g}^{-1} \cdot{ }^{64}$ Owing to its high electronic conductivity, high surface area, and large number of active sites (edges and defects in graphene layers) for $\mathrm{Li}^{+}$storage and short diffusion distance, graphene was used to hybridize with other active materials. Layered $\mathrm{MoS}_{2}$ /graphene composites exhibited a high specific capacity of $\sim 1100 \mathrm{~mA} \mathrm{~h} \mathrm{~g}^{-1}$ at $100 \mathrm{~mA}$ $\mathrm{g}^{-1}$ and no capacity fading after 100 cycles. The synergistic effects between layered $\mathrm{MoS}_{2}$ and graphene preserved the high conductivity and greatly enhanced the electrochemical activity. ${ }^{65} 3 \mathrm{D}$ porous monolayer $\mathrm{MoS}_{2}$-graphene composite aerogels also exhibited a large reversible capacity up to $1200 \mathrm{~mA} \mathrm{~h} \mathrm{~g}^{-1}$, and good cycling stability and rate performance. ${ }^{66}$ Metal oxide nanoparticles anchored on graphene surfaces in a hybrid form also showed significant improvement in electrode performance. ${ }^{67,68}$

\subsection{Lithium transition metal oxide-based cathodes}

Future applications of electronic devices and electric vehicles demand a significant power increase. As aforementioned, a shorter $\mathrm{Li}^{+}$diffusion distance and larger electrolyte/electrode interface in cathode nanomaterials would enable much higher reaction rate. More importantly, size reduction could initiate certain phenomena which can't be observed in large particles. Olivine $\mathrm{LiFePO}_{4}$ has demonstrated reversible extraction of $\mathrm{Li}^{+}$ involving a Li-poor phase $\mathrm{FePO}_{4}$ and a Li-rich phase $\mathrm{LiFePO}_{4}{ }^{3}$ Nucleation of the second phase and growth through interface motion during this process severely limited the rate capability of such materials. Ceder et al. ${ }^{69}$ discovered that ultrahigh discharge rate comparable to those of supercapacitors can be achieved when the $\mathrm{LiFePO}_{4}$ particle size was reduced to around $50 \mathrm{~nm}$ (Fig. 4a). Further study proved that a nonequilibrium solid solution phase ${ }^{70}$ that span the entire composition between two thermodynamic phases ${ }^{71}$ can be formed in nanoparticulate $\mathrm{LiFePO}_{4}$ at high rates (Fig. $4 \mathrm{~b}$ and c). ${ }^{72}$ Similar phenomenon was also observed in nanosized $\mathrm{Na}_{x} \mathrm{FePO}_{4}$ and a high rate $\mathrm{Na}$ insertion/desertion could be achieved. ${ }^{73}$
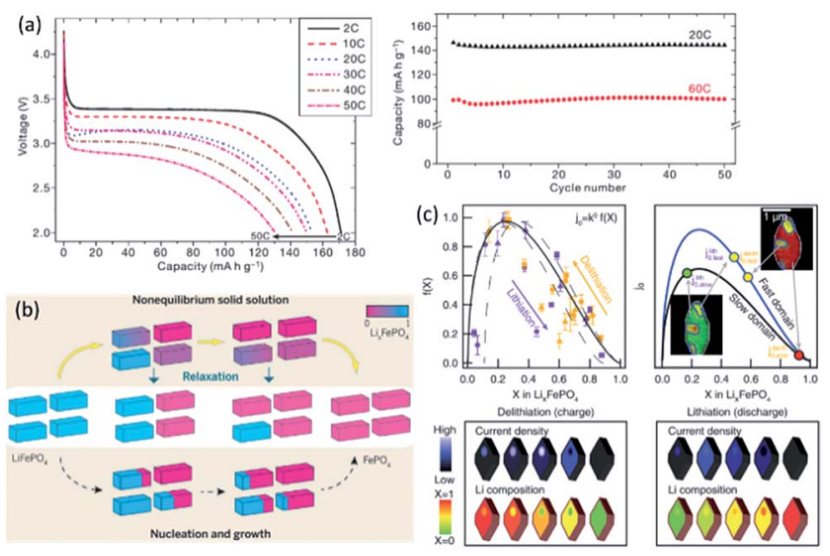

Fig. 4 (a) Rate capability and capacity retention for $\mathrm{LiFePO}_{4}$ synthesized at $600{ }^{\circ} \mathrm{C}$. Reproduced with permission from ref. 69, copyright 2009, Nature Publishing Group. (b) Phase transformation from $\mathrm{LiFePO}_{4}$ (blue) to $\mathrm{FePO}_{4}$ (red). Reproduced with permission from ref. 71, copyright 2014, The American Association for the Advancement of Science. (c) Quantifying the insertion kinetics and exchange current density. Reproduced with permission from ref. 72 , copyright 2016, The American Association for the Advancement of Science.

Nanosized $\mathrm{LiFePO}_{4}$ has also been utilized as a coating layer providing a fast $\mathrm{Li}^{+}$transportation pathway. Pan et al. ${ }^{74}$ managed to coat $50 \mathrm{~nm}$ crystal oriented $\mathrm{LiFePO}_{4}$ onto $\mathrm{LiNi}_{0.5^{-}}$ $\mathrm{Mn}_{0.3} \mathrm{Co}_{0.2} \mathrm{O}_{2}$ (NMC532) and created a core-shell cathode material (Fig. 5a). It showed superior cycling stability with a discharge capacity of $168.5 \mathrm{~mA} \mathrm{~h} \mathrm{~g}^{-1}$ (cycling between 3 and $4.5 \mathrm{~V}, 7.2 \%$ capacity loss) and $173.3 \mathrm{~mA} \mathrm{~h} \mathrm{~g}^{-1}$ (cycling between 3 and $4.6 \mathrm{~V}, 8.5 \%$ capacity loss) after 150 cycles at $\mathrm{C} / 3$, respectively (Fig. 5b).

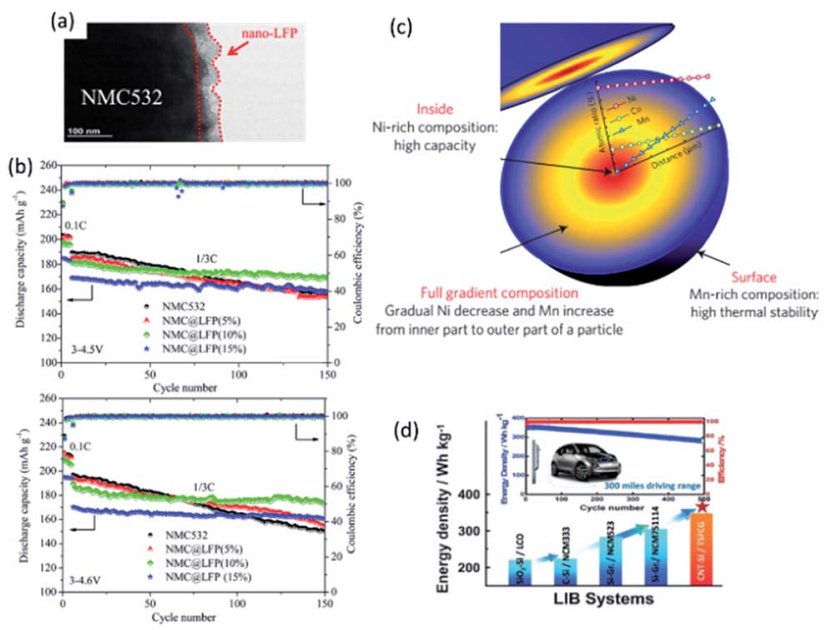

Fig. 5 (a) TEM image of NMCQLFP, and (b) cycling performance of pristine NMC532 and NMC@LFP (5, 10,15\%) at different rates and cutoff voltages. Reproduced with permission from ref. 74, copyright 2016, American Chemical Society. (c) Schematic diagram of the FCG lithium transition-metal oxide particle with $\mathrm{Ni}$-rich core and $\mathrm{Mn}$-rich outer layer. Reproduced with permission from ref. 75, copyright 2012, Nature Publishing Group. (d) Schematic illustration of LIBs based on CNT-Si anode and two-sloped FCG cathode for vehicle application. ${ }^{76}$ 
Another example that illustrates the benefits of nanostructured materials is the full concentration gradient (FCG) layered metal oxide (Fig. 5c). ${ }^{75}$ Although Ni-rich layered lithium transition metal oxides have high specific capacity and relatively low cost, they suffer severely from poor thermal stability at fully charged state and insufficient cycle life. Using a nanofunctional full-gradient approach, high energy density of the Ni-rich core and the high thermal stability and long life of the Mn-rich outer layers can be harnessed. High rate performance could also be realized from aligned needle-like nanosized primary particles. ${ }^{75} \mathrm{~A}$ full cell with an energy density of $350 \mathrm{~W} \mathrm{~h}$ $\mathrm{kg}^{-1}$ and excellent capacity retention for 500 cycles at $1 \mathrm{C}$ has been demonstrated accordingly (Fig. $5 \mathrm{~d}$ ). ${ }^{76} 1 \mathrm{D}$ nanowire LT$\mathrm{LiCoO}_{2}$ based on SBA-15 and highly ordered spinel $\mathrm{LiNi}_{0.5^{-}}$ $\mathrm{Mn}_{1.5} \mathrm{O}_{2}$ array also showed superior electrochemical performance compared with bulk materials. ${ }^{77,78}$

\subsection{Nanostructures in $\mathrm{Li}-\mathrm{S}$ batteries}

The maximum energy that can be stored and delivered in current LIB cathodes (such as layered oxides, polyanionic and spinel materials) is still too low to meet some demands like transportation applications. ${ }^{79}$ In contrast, Li-S batteries $(\mathrm{S}+$ $2 \mathrm{Li}^{+}+2 \mathrm{e}^{-} \rightarrow \mathrm{Li}_{2} \mathrm{~S}$ ) can deliver a theoretical energy density of $2567 \mathrm{~W} \mathrm{~h} \mathrm{~kg}^{-1}$ or $2199 \mathrm{~W} \mathrm{~h} \mathrm{~L}^{-1},{ }^{80}$ making Li-S promising for future battery systems. However, its large scale application is impeded by three main challenges: (1) sluggish kinetics ascribed to the insulating nature of $S$ and its lithiated products $\mathrm{Li}_{2} \mathrm{~S}_{x}$; (2) collapse in electrode structure due to large volume change during lithiation; and (3) a shuttle effect and rapid capacity fade due to dissolution of intermediates in the electrolyte (Fig. 6a). ${ }^{81}$ Such challenges can be tackled by rational design of nanostructures with interconnected electron pathways and ion diffusion channels.

The first category of nanostructured sulfur cathodes lies in carbon materials and sulfur nanoparticles. It has been reported that sulfur nanoparticles encapsulated in nanoporous carbon matrix with ultrahigh sulfur loading (88.9 wt\%) exhibited a high overall discharge capacity of $649.4 \mathrm{~mA} \mathrm{~h} \mathrm{~g}{ }^{-1} .{ }^{82}$ The porous structure enabled higher capacity retention $(84.6 \%)$ and $\mathrm{CE}$ $(97.4 \%)$ after 50 cycles at $\mathrm{C} / 10$, attributed to the resulting electronic and ionic transfer channel. Sulfur content was further increased to $90 \%$ in a composite with nanoscale distribution of $\mathrm{S}$ in 3D porous graphitic carbon. This material has a high specific capacity $\left(1382,1242\right.$ and $1115 \mathrm{~mA} \mathrm{~h}^{-1}$ at $0.5,1$ and $2 \mathrm{C}$, respectively), long cycling life (capacity decay of $0.039 \%$ per cycle over 1000 cycles at $2 \mathrm{C}$ ), and excellent rate capability. ${ }^{83}$ Carbon nanotubes, ${ }^{\mathbf{8 4}}$ carbon nanofibers ${ }^{\mathbf{8 5}}$ and hollow spheres ${ }^{\mathbf{4 4}}$ also have demonstrated superior electrochemical performance with high specific capacity, excellent cycling stability and rate capability. To strengthen the interaction between nonpolar carbon and polar sulfur cluster and polysulfides, Cui et al. modified the hollow carbon nanotube surface with amphiphilic polymers, ${ }^{\mathbf{8 6}}$ which allowed lithium sulfides to bind strongly with the carbon surface and resulted in less than 3\% decay over the first 100 cycles at $\mathrm{C} / 2$. The capacity retention was $>80 \%$ for more than 300 cycles with $\mathrm{CE} \sim 99 \%$. Carbon surface can be
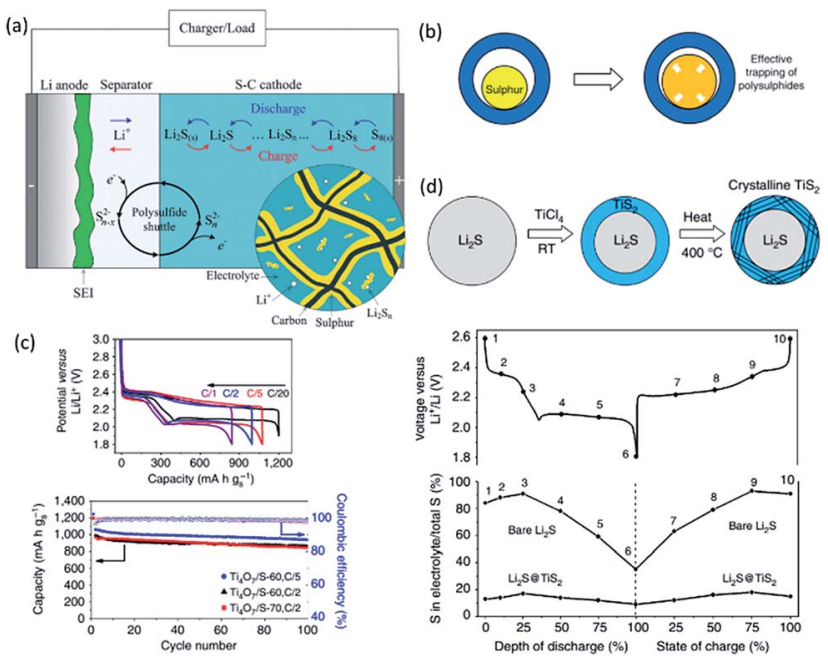

Fig. 6 (a) Illustration of the dissolution and shuttling of polysulfides in a Li-S cell. ${ }^{81}$ (b) A yolk-shell structure with internal void space can accommodate the volume expansion of sulphur for effective trapping of polysulphides. Reproduced with permission from ref. 94, copyright 2013, Nature Publishing Group. (c) Electrochemical performance of $\mathrm{Ti}_{4} \mathrm{O}_{7} / \mathrm{S}$ electrodes. Reproduced with permission from ref. 98, copyright 2014, Nature Publishing Group. (d) Schematic of $\mathrm{Li}_{2} \mathrm{~S} \propto \mathrm{TiS} 2$ coreshell nanostructures, and reduced loss of total sulfur into the electrolyte detected at various intermediate stages of cycling, in comparison with bare $\mathrm{Li}_{2} \mathrm{~S}$ cathodes. Reproduced with permission from ref. 99, copyright 2014, Nature Publishing Group.

functionalized via elemental doping to create chemical anchoring sites. Nitrogen-doping on mesoporous carbon nanospheres and carbon nanotubes endowed electrondonating ability. ${ }^{87}$ The as-obtained composite delivered a high

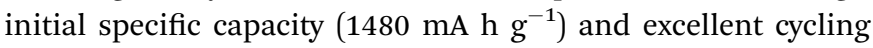
stability (90\% retention over 200 cycles after activation) with 70 wt\% sulfur and $5 \mathrm{mg} \mathrm{cm}^{-2}$ areal loading. Other doping elements (such as S, B, O and P) have also been extensively explored for Li-S batteries. Graphene nanosheets with heteroatom doping built strong bound interface with sulfur and polysulfide to optimize the electrochemical performance. A high initial discharge capacity of $1302 \mathrm{~mA} \mathrm{~h} \mathrm{~g} \mathrm{~g}^{-1}$ and retained discharge capacity of $978 \mathrm{~mA} \mathrm{~h} \mathrm{~g}^{-1}$ after 200 cycles at C/10 were obtained in a recent work. ${ }^{\mathbf{8}}$

To further increase the anchoring ability of host materials, nanostructured polar inorganic materials such as metal oxides and sulfides have been investigated. Stronger adsorption of host materials towards polysulfides renders higher sulfur utilization and longer life span. In an early work, ${ }^{89}$ mesoporous silica SBA15 (ref. 90) was used as a reservoir for S/C nanocomposite. The initial discharge capacity of the cell was $960 \mathrm{~mA} \mathrm{~h} \mathrm{~g}^{-1}$ and a capacity of about $650 \mathrm{~mA} \mathrm{~h} \mathrm{~g}^{-1}$ was maintained after 40 cycles. The sulfur content in the electrolyte was reduced from $54 \%$ to $23 \%$ with the presence of $\mathrm{SiO}_{2}$. In another work, ${ }^{91}$ a bifunctional $\mathrm{MnO}_{2}$ shell with $50 \mathrm{~nm}$ thick $\mathrm{MnO}_{2}$ shell coated on sulfur particles provided physical confinement and chemical interaction and demonstrated excellent efficiency in trapping the polysulfides even with $85 \%$ sulfur loading. In addition, stable $\mathrm{Li}-\mathrm{S}$ cycling performance has been achieved by directly crystallizing 
nanoshells of $\mathrm{MnO}_{2}$ on micrometer-sized sublimed sulfur with $480 \mathrm{~mA} \mathrm{~h} \mathrm{~g}^{-1}$ after 800 cycles and only $0.048 \%$ capacity fade per cycle. Due to their intrinsic low electronic conductivity, conductive scaffold is often combined to create a robust electrode. Hollow carbon fibers (HCF) filled with intrinsic insulating $\mathrm{MnO}_{2}$ nanosheets was recently reported by Lou et al. ${ }^{92}$ With $71 \mathrm{wt} \%$ and $3.5 \mathrm{mg} \mathrm{cm}{ }^{-2}$ of sulfur, the $\mathrm{MnO}_{2} @ \mathrm{HCF} / \mathrm{S}$ composite electrode delivered a specific capacity of $1161 \mathrm{~mA} \mathrm{~h}$ $\mathrm{g}^{-1}$ or $4.1 \mathrm{~mA} \mathrm{~h} \mathrm{~cm}{ }^{-2}$ at $\mathrm{C} / 20$ and maintained stable cycling performance at $\mathrm{C} / 2$ over 300 cycles. Attributed to its good electronic conductivity as well as the polar surface, titanium oxides have also been applied extensively in Li-S batteries. For example, the soluble lithium polysulfides are preferentially absorbed within the pores of the nanoporous titania at intermediate discharge/charge. The addition of $\mathrm{TiO}_{2}$ with a $5 \mathrm{~nm}$ pore diameter enabled $37 \%$ improvement in capacity retention after 100 cycles..$^{93}$ Using a yolk-shell architecture with internal void space to accommodate the volume expansion of sulfur (Fig. 6b), Cui et al. demonstrated an initial specific capacity of $1030 \mathrm{~mA} \mathrm{~h} \mathrm{~g}^{-1}$ at $\mathrm{C} / 2$ and $\mathrm{CE}$ of $98.4 \%$ over 1000 cycles in a coin cell with $0.4-0.6 \mathrm{mg} \mathrm{cm}{ }^{-2}$ of sulfur. ${ }^{94}$ The capacity decay after 1000 cycles was $0.033 \%$ per cycle. Hydrogen treatment has been proven effective to produce $\mathrm{Ti}^{3+}$ and improve the electronic conductivity of $\mathrm{TiO}_{2} \cdot{ }^{95}$ Hydrogen-treated $\mathrm{TiO}_{2}$ inverse opal with small dimensions of nanopores effectively confined polysulfides by both physical trapping and surface chemical adsorption. ${ }^{96}$ The fabricated sulfur cathode could deliver a high initial specific capacity of about $1100 \mathrm{~mA} \mathrm{~h} \mathrm{~g}^{-1}$, with a reversible capacity of about $890 \mathrm{~mA} \mathrm{~h} \mathrm{~g}^{-1}$ after 200 cycles at $\mathrm{C} / 5$. The $\mathrm{CE}$ was also maintained at about $99.5 \%$ during cycling. $\mathrm{TiO}_{2}$ nanotubes, nanofibers, hollow spheres and nanoparticles have all been reported to improve the performance of $\mathrm{Li}-\mathrm{S}$ batteries. Conductive metallic Magneli phase $\mathrm{Ti}_{4} \mathrm{O}_{7}$ is another promising sulfur host. ${ }^{97}$ Nanocrystalline $\mathrm{Ti}_{4} \mathrm{O}_{7}$ impregnated with $60-70$ $\mathrm{wt} \%$ sulfur provided a discharge capacity of $1070 \mathrm{~mA} \mathrm{~h} \mathrm{~g} \mathrm{~g}^{-1}$ at intermediate rates and good capacity retention (Fig. 6c). ${ }^{98}$

Given the conductive nature of metal chalcogenides and stronger sulfiphilic property of these sulfur containing species, metal sulfides offer more benefits and constitute another promising family as host materials for Li-S batteries. Using 2D conductive $\mathrm{TiS}_{2}$ to encapsulate $\mathrm{Li}_{2} \mathrm{~S}$ core particles in a $20 \mathrm{~nm}$ thick shell (Fig. 6d), ${ }^{99}$ a high specific capacity of $503 \mathrm{~mA} \mathrm{~h} \mathrm{~g}^{-1}$ under $4 \mathrm{C}$ as well as high areal capacity of $3 \mathrm{~mA} \mathrm{~h} \mathrm{~cm}{ }^{-2}$ was obtained. A thinner shell would have a faster fade rate due to its insufficient thickness to protect the core, while a thicker shell hindered rate performance. To further increase sulfur loading, $\mathrm{S}_{8}$ was infused into nanoporous $\mathrm{TiS}_{2}$ foams. ${ }^{100}$ The hybrid cathodes demonstrated high areal specific capacity $(9 \mathrm{~mA} \mathrm{~h}$ $\mathrm{cm}^{-2}$ ) and capacity retention, even with $\sim 40 \mathrm{mg} \mathrm{cm}{ }^{-2}$ and high current density $\left(10 \mathrm{~mA} \mathrm{~cm}{ }^{-2}\right)$. Another highly conductive $\mathrm{Co}_{9} \mathrm{~S}_{8}$ could form an interconnected graphene-like nano-architecture ${ }^{101}$ where the 3D interconnected structure with hierarchical porosity not only manifested enhancement in the cycling stability (fade $0.045 \%$ per cycle over 1500 cycles at $\mathrm{C} / 2$ ) compared to standard porous carbons but also realized a high-loading sulfur electrode (up to $75 \mathrm{wt} \%$ sulfur and $4.5 \mathrm{mg}$ $\mathrm{cm}^{-2}$ ). Another host material is $\operatorname{CoS}_{2}$. When incorporated into carbon/sulfur cathodes, a slow capacity decay of $0.034 \%$ per cycle at $2 \mathrm{C}$ and a high initial capacity of $1368 \mathrm{~mA} \mathrm{~h} \mathrm{~g}^{-1}$ at $\mathrm{C} / 2$ were achieved. ${ }^{102} \mathrm{FeS}_{2},{ }^{103} \mathrm{ZnS},{ }^{104} \mathrm{WS}_{2}$ (ref. 105) and other various sulfides ${ }^{80}$ have been used as host materials as well. Although nanostructured carbon, metal oxides and sulfides have demonstrated outstanding ability to create a cathode with high sulfur utilization and long cycle life, material abundance, areal loading and viable anode should be considered towards the practical application of $\mathrm{Li}-\mathrm{S}$ batteries.

\section{Nanostructured coatings for advanced electrodes}

Many electrode materials of LIBs encounter critical issues including: huge volume expansion, low ionic/electronic conductivities, and/or side reactions with electrolytes etc. Surface modification of electrode materials by employing a thin nanoscale layer has proved effective way for improving the electrochemical performance of LIBs. ${ }^{106}$ Different types of nanoscale coatings depending on the nature of electrodes have been developed, such as carbon based materials, oxides, fluoride, phosphates, and other ionic and electronic conductive species. ${ }^{107}$ Associated with these benefits of the coating chemistries, the structure design for effectively combining the advantages of the coatings and active materials, such as coreshell ${ }^{108}$ and hollow shell, ${ }^{109}$ has been also performed to engender much improvement of the LIB electrodes. This section reviews the recent progress in nanostructured coatings for developing high-performance LIB components, including metallic anodes, metal oxide anodes, Li-rich layered oxide cathodes, high-voltage spinel cathodes, and sulfur based cathodes. Great interests have been put in multifunctional capabilities and unique characteristics of the surface modifications for advanced LIB techniques.

\subsection{Thin films on metallic Li and Li-alloy-based anodes}

Extensive research has been focused on battery chemistries with metallic anodes ( $\mathrm{Li}, \mathrm{Si}, \mathrm{Ge}, \mathrm{Sn}$, etc.) mainly due to their high specific capacities. For Li metal, it is an attractive anode material, possessing a high theoretical specific capacity (3860 mA h $\left.\mathrm{g}^{-1}\right)$, low density $\left(0.534 \mathrm{~g} \mathrm{~cm}^{-3}\right)$, and the lowest electrochemical potential $(-3.04 \mathrm{~V} v s$. standard hydrogen electrode). Although metallic Li anode is highly interesting for high-energy batteries such as Li-S battery, Li-air battery, and other advanced systems, the dendritic $\mathrm{Li}$ formation and high chemical reactivity of $\mathrm{Li}$ with most electrolytes remain challenging. Graphene, ${ }^{110}$ polymer membranes ${ }^{111}$ and ceramic electrolytes ${ }^{112}$ have been used as chemically and physically protective layers on $\mathrm{Li}$ anode. However, there still exist issues with safety and efficiency during prolonged cycles. More efforts to build a robust surface layer to suppress the growth of Li dendrites and enhance compatibility between $\mathrm{Li}$ anode and electrolyte after long-time operations are driven for enabling a variety of batteries using Li metal with high energy storage.

Recently, Yan et al. ${ }^{113}$ demonstrated a promising novel electrode design by growing 2D atomic crystal layers including 
hexagonal boron nitride (h-BN) and graphene directly on $\mathrm{Cu}$ metal current collectors. They used the method of chemical vapor deposition (CVD) developed recently for synthesis of large-area h-BN. The thickness of the film was determined to vary from 1 to 10 atomic layers, depending on the growth time and pressure. Smooth Li metal deposition without dendritic and mossy Li formation was realized. Their results showed stable cycling over 50 cycles with CE $\sim 97 \%$ in organic carbonate electrolyte with current density and areal capacity up to $2 \mathrm{~mA}$ $\mathrm{cm}^{-2}$ and $5 \mathrm{~mA} \mathrm{~h} \mathrm{~cm}{ }^{-2}$, respectively. ${ }^{114}$ Both graphene and h-BN were summarized with the following attractive properties: (1) they are known to be chemically inert and stable against most chemicals including Li metal; (2) their single atomic layers have very strong mechanical strength, resulted from strong interlayer bonding; (3) no chemical species can diffuse through the layers and $\mathrm{Li}$ metal cannot move through the ring pore, either; and (4) despite the large in-plane strength, 1-10 layers of graphene and h-BN are highly flexible due to their ultrathin thickness $(<10 \mathrm{~nm})$.

Liu et al. ${ }^{\mathbf{1 1 4}}$ reported a new strategy to address the issue of dendrite growth of metallic Li by a polyimide-coating layer with vertical nanoscale channels of high aspect ratio. The nanosized channels with high aspect ratio were able to divide the space above the anode into small confinements. Thus, $\mathrm{Li}^{+}$could prefer to move along the normal direction of the electrode rather than the parallel direction. The magnitude of $\mathrm{Li}^{+}$flux in each nanochannel could be relatively homogeneous during Li deposition, resulting in a uniform nucleation and growth, and the $\mathrm{Li}$ deposit could not grow into elongated metal filaments. Meanwhile, the volumetric expansion of the Li deposition could be also partially negated within the volume of the pores due to the fixed thickness of the coating. More importantly, the porous polymer membrane contacted with the current collector tightly, which avoided the possibility of its lift up by the deposition of Li metal. Their results showed that the cells with modified electrodes exhibited significantly improved CE of $97.6 \%$ over 240 cycles, 92.9\% over 150 cycles, and $88.6 \%$ over 140 cycles, respectively, at current densities of 1,2 , and $3 \mathrm{~mA} \mathrm{~cm} \mathrm{~cm}^{-2}$. In sharp contrast, the cells using bare electrode showed rapid decay after 125,75 , and 50 cycles, respectively. Subsequently, they reported a nanoporous, flexible, and electrochemically stable coating of silica@poly(methyl methacrylate) ( $\mathrm{SiO}_{2} @-$ PMMA) core-shell nanospheres as a stable layer on Li metal anode. ${ }^{\mathbf{1 1 5}}$ The cell with bare $\mathrm{Cu}$ electrode showed a gradual decrease in CE, which eventually decayed to $68 \%$ and $56 \%$ after 50 cycles at 0.5 and $1 \mathrm{~mA} \mathrm{~cm}{ }^{-2}$, respectively. For the $\mathrm{Cu}$ electrode coated with $\mathrm{SiO}_{2} @ P M M A$ nanospheres of 450@20, 550@10, and 550@20 nm, the CE after 50 cycles was about 87\%, $83 \%$, and $81 \%$ at $0.5 \mathrm{~mA} \mathrm{~cm} \mathrm{~cm}^{-2}$, respectively. When tested at a higher current density of $1 \mathrm{~mA} \mathrm{~cm}^{-2}$, a CE of $90 \%$ after 50 cycles was achieved for the modified electrode with 550@10 nm nanosphere coating. It was well illustrated that the core-shell structure produced a synergistic effect between the core and shell to prevent Li dendrite growth. Compared to bare electrode, dendritic Li with large specific surface area could continuously decompose the electrolyte, resulting in low CE and short cycle life (Fig. 7a). An explanation for the beneficial effect of the

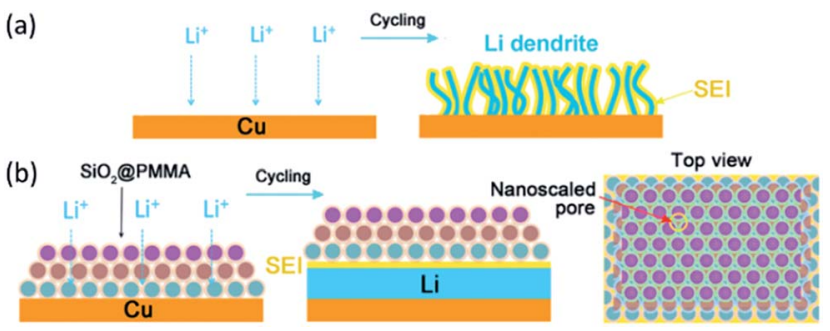

Fig. 7 Schematic diagrams of different Li anode structures. (a) A thin film of SEl layer forms on bare Cu surface. Volumetric changes during the Li deposition can easily break the SEI layer, leading to ramified growth of Li dendrites and consumption of the electrolyte. (b) Modified $\mathrm{Cu}$ electrode coated with a $\mathrm{SiO}_{2}$ (aPMMA nanosphere layer. The volumetric change of $\mathrm{Li}$ deposition/dissolution is accommodated by the coating of $\mathrm{SiO}_{2}$ (aPMMA nanospheres. Nanoscaled pores are able to suppress lithium dendrites. Each monolayer is given a different color to indicate the packing of nanospheres. Reproduced with permission from ref. 115, copyright 2017, American Chemical Society.

coating of $\mathrm{SiO}_{2} @ P M M A$ core-shell nanospheres were proposed, as shown in Fig. 7b. They demonstrated that the $\mathrm{SiO}_{2}$ core with high Young's modulus could suppress Li dendrite growth. The nanoscaled pores formed by coating $\mathrm{SiO}_{2} @ \mathrm{PMMA}$ core-shell nanospheres were so small that Li dendrites cannot penetrate the membrane, but $\mathrm{Li}^{+}$could diffuse without being blocked. The PMMA shell can hold the $\mathrm{SiO}_{2}$ spheres together to form a robust and flexible membrane that could accommodate volume change during Li deposition/dissolution without cracking and could prevent reaction between $\mathrm{SiO}_{2}$ and $\mathrm{Li}$ metal.

Recently, Si has been found to offer ten times more energy density as compared to carbon anode. However, Si anode suffers two major drawbacks: (1) low electronic conductivity; (2) large volume expansion during charging. To utilize the high energy density of Si while minimize its drawbacks, various $\mathrm{Si}$-carbon composites $^{116-118}$ have been developed and demonstrated to have enhanced performance. Unfortunately, cracking associated with volume expansion generally still occurs, leading to poor cycle stability and rate capability. To further improve electrochemical properties of $\mathrm{Si}$ anode, thin surface coatings with various materials, such as oxide $\mathbf{1 1 9 , 1 2 0}^{10}$ and carbon based materials, ${ }^{121}$ have attracted considerable attention as a promising candidate approach to accommodate the large volume expansion and enhance the cyclability of Si electrodes. Xiao et al. ${ }^{122}$ deposited a $5 \mathrm{~nm} \mathrm{Al}_{2} \mathrm{O}_{3}$ coating on $\mathrm{Si}$ anode by means of atomic layer deposition (ALD), and characterized the SEI features for both bare and $\mathrm{Al}_{2} \mathrm{O}_{3}$-coated $\mathrm{Si}$ anodes using time-offlight secondary ion mass spectrometry. In contrast, the SEI thickness of $\mathrm{Al}_{2} \mathrm{O}_{3}$-coated $\mathrm{Si}$ anode was only a few nanometers, which was obviously smaller than that of bare Si anode (about 20-30 nm). The SEI layer on the $\mathrm{Al}_{2} \mathrm{O}_{3}$-coated $\mathrm{Si}$ anode contained much less $\mathrm{Li}_{2} \mathrm{CO}_{3}$ than that on bare $\mathrm{Si}$ anode. They ascribed this to the insulating $\mathrm{Al}_{2} \mathrm{O}_{3}$ coating, preventing electrons from reaching the anode surface to engender the decomposition of the electrolyte. Moreover, $\mathrm{LiAlO}_{2}$ was demonstrated to form in the top surface of SEI on the $\mathrm{Al}_{2} \mathrm{O}_{3}$ coated $\mathrm{Si}$ anode, reducing the energy barriers against the insertion of $\mathrm{Li}^{+}$and thus enhancing the kinetics of $\mathrm{Li}^{+}$transfer. 
However, the details of these reactions at the atomic scale have not yet been understood.

Liu et al. ${ }^{123}$ encapsulated Si anode materials with conductive polymer that had the elastic advantage during the charge and discharge process of $\mathrm{Si}$ anode. Meanwhile, conductive additives were not needed for the modified $\mathrm{Si}$ anode because of good conductive pathway to all the $\mathrm{Si}$ particles provided by the conductive polymer. This is an efficient way to enhance the loading of Si and increase the energy density. Combined with the high theoretical capacity of Si core $\left(4200 \mathrm{~mA} \mathrm{~h} \mathrm{~g}^{-1}\right)$, Chang et al. $^{\mathbf{1 2 4}}$ deposited multilayered reduced graphene oxide (RGO) with $\mathrm{Si}$ nanoparticles in between each layer, intending to suppress the issue of volume expansion. The RGO layers closest to each Si nanoparticle could allow enough space for the $\mathrm{Si}$ nanoparticle to expand during the lithiation process. The RGO layers away from each Si nanoparticle could provide mechanical stability due to the formation of 2D networks of graphite based on van de Waals forces. Moreover, the RGO layers possessed high electrical conductivity favoring the connection of each isolated Si nanoparticle.

For TiN in particular, its high electrical conductivity (resistivity of $25 \mu \Omega \mathrm{cm}$ ) is one of its most important attributes. Nanoscale TiN coating was deposited on Si NWs by ALD, and to a lesser extent by magnetron sputtering. A $5 \mathrm{~nm}$ thick TiN coating resulted in optimum cycling capacity retention $(55 \% \mathrm{vs}$. $30 \%$ for the bare Si NWs, after 100 cycles) and CE (98\% vs. 95\%, at 50 cycles), also enhanced rate capacity retention (e.g. 740 $\mathrm{mA} \mathrm{h}{ }^{-1}$ vs. $330 \mathrm{~mA} \mathrm{~h} \mathrm{~g}^{-1}$, at $5 \mathrm{C}$ ). The results indicated that the thin TiN coating significantly improved the cycling performance of Si NWs anode. Moreover, they employed a variety of advanced analytical techniques such as electron energy loss spectroscopy to elucidate the origin of these effects. The conformal $5 \mathrm{~nm}$ TiN remained sufficiently intact to limit the SEI growth, which in turn both improved the overall $\mathrm{CE}$ and reduced the life-ending delamination of the nanowire assemblies from the underlying current collector. ${ }^{\mathbf{1 2 5}}$

To improve the electronic conduction properties of nanostructured $\mathrm{Si}$ anode, one way is to use metallic coatings. ${ }^{\mathbf{1 2 6}}$ A metallic $\mathrm{Cu}$ coating partially deposited on the $\mathrm{Si}$ NWs was reported by McDowell et al. ${ }^{127}$ The Cu coating is only deposited on one side of the Si NWs for remaining transport pathways of $\mathrm{Li}^{+}$. It was observed that the width and length of the Cu-coated Si NWs almost unchanged during lithiation. Hence, the $\mathrm{Cu}$ coating not only provides high electrical conductivity in the composites, but also maintains structural integrity.

Jeong et al. ${ }^{\mathbf{1 2 8}}$ encapsulated Si nanoparticles with $\mathrm{TiO}_{2-x} / \mathrm{C}$ nanocomposite to form core-shell structured $\mathrm{Si}$ nanoparticles@TiO ${ }_{2-x} / \mathrm{C}$ (SiNPs@T/C) mesoporous microfiber composite by an electrospinning method. The cycling performance and rate capability of the SiNPs@T/C were exhibited in Fig. 8a and b. For comparison, the simply mixed $\mathrm{Si}-\mathrm{TiO}_{2}-\mathrm{C}$ electrode in the same weight ratio with the SiNPs@T/C electrode (the Si content in the SiNPs@T/C was $\sim 43 \%$ ) was also tested. When cycled at C/5 and 1C, the SiNPs@T/C displayed excellent cycling performance with almost the same capacity retention (i.e. $90 \%$ of the initial capacity after 50 cycles). The
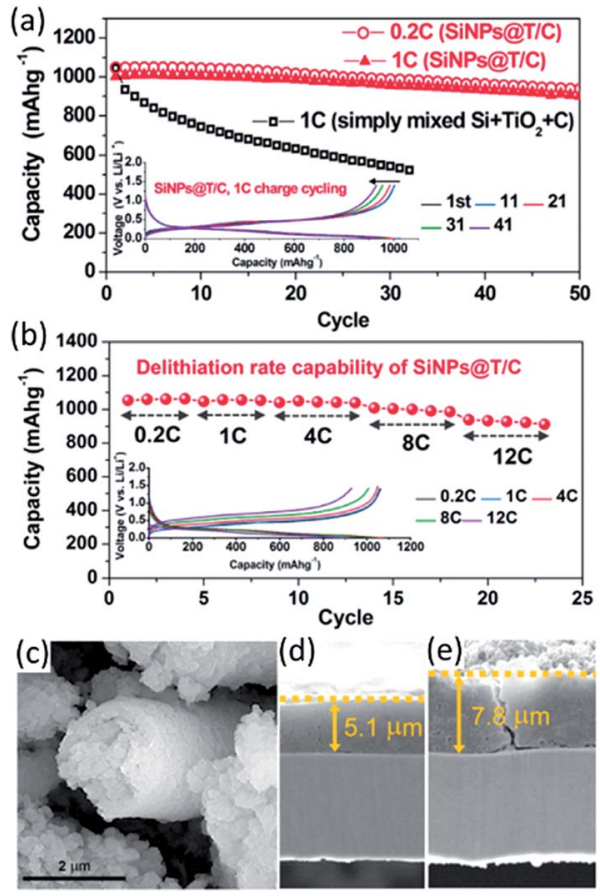

Fig. 8 (a) Capacity retention of SiNPs $A T / C$ during cycling and the corresponding voltage profiles (inset). (b) Rate capability of SiNPs@T/C and the corresponding voltage profiles (inset). (c) SEM image of SiNPs@T/C after 50 cycles (lithiated state). The cross-sectional SEM images of SiNPs@T/C electrode (d) before cycling and (e) after 50 cycles (lithiated state). Reproduced with permission from ref. 128, copyright 2014, American Chemical Society.

SiNPs@T/C also exhibited outstanding rate capability, where a high capacity of $939 \mathrm{~mA} \mathrm{~h} \mathrm{~g}^{-1}$ was observed even at $12 \mathrm{C}(12 \mathrm{~A}$ $\mathrm{g}^{-1}$ ), which is $89 \%$ of the initial capacity at $\mathrm{C} / 5$. The SEM images of the SiNPs@T/C particle and the cross section of the SiNPs@T/C electrode after 50 cycles were shown in Fig. 8c-e. Significant collapse of the fibrous core-shell structure cannot be observed even after 50 cycles. Also, the volume expansion after the 50th discharge was still $\sim 53 \%$, which was almost the same as the value after the first discharge step. The improved electrochemical properties were mainly ascribed to the structure reserving void space therein, as well as oxygen deficient $\mathrm{TiO}_{2-x}$ and carbon providing an enhanced electrical pathway. Similarly, the double shells (i.e. carbon inner shell and $\mathrm{TiO}_{2}$ outer shell) were deposited on Si anodes, avoiding the direct contact of $\mathrm{Si}$ with electrolyte. With this architecture, the advantages of core-shell-shell nanostructures lay in the presence of the internal mesoporous space and the mechanically robust $\mathrm{TiO}_{2}$ layer. The elaborate double-shell Si nanoparticles were proven to show excellent Li-storage properties. It delivered high reversible capacity of $1726 \mathrm{~mA} \mathrm{~h} \mathrm{~g}^{-1}$ over 100 cycles, with outstanding cyclability of $1010 \mathrm{~mA} \mathrm{~h} \mathrm{~g}^{-1}$ at $0.42 \mathrm{~A}$ $\mathrm{g}^{-1}$ and high CE of $>98 \%$ after 710 cycles. ${ }^{129}$ The carbon inner shell was considered to improve overall conductivity of the Sibased electrode and the $\mathrm{TiO}_{2}$ outer shell served as a rigid layer to achieve high structural integrity of the double-shell structure. 


\subsection{Thin films on metal oxide anodes}

Metal oxides used as anode materials for LIBs have received extensive attention due to their higher theoretic specific capacities than graphite and relatively smaller volume change than metal anodes. Unfortunately, they usually suffer from a severe capacity fade and poor cycling performance caused by volume expansion or the risk of secondary reactions during cycling. The widely used strategy is to coat the anodes with carbon nanomaterials ${ }^{\mathbf{1 3 0 , 1 3 1}}$ that could accommodate the volume change based on their elastic features and increase the electronic conductivity of the anode materials, resulting in a better capacity retention and cyclic performance. For example, it was found that polymerization of pyrrole monomers lead to the simultaneous oxidation of $\mathrm{Fe}_{2} \mathrm{O}_{3}$ and polypyrrole (PPy) coating process, resulting in the successful formation of hierarchical nanocages of $\mathrm{Fe}_{3} \mathrm{O}_{4} @ P P y$. By using as-prepared hierarchical $\mathrm{Fe}_{3} \mathrm{O}_{4} @ P P y$ nanocages as the anode, they exhibited excellent electrochemical performances, such as improved large reversible capacity, rate capability, and long-term cycling stability. ${ }^{\mathbf{1 3 2}}$ Similarly, the synthesized $\mathrm{Mn}_{3} \mathrm{O}_{4}$ samples with a tetragonal structure (space group I4 $/$ amd) displayed nanorodlike morphology, with a width of 200-300 nm and a thickness of 15$20 \mathrm{~nm}$. The carbon layers with a thickness of $5 \mathrm{~nm}$ could be homogeneously coated on the $\mathrm{Mn}_{3} \mathrm{O}_{4}$ nanorods, and the $\mathrm{Mn}_{3} \mathrm{O}_{4} @ \mathrm{C}$ samples displayed enhanced capacity retention on cycling. Even after 50 cycles, the products remained stable capacity of $473 \mathrm{~mA} \mathrm{~h} \mathrm{~g}^{-1}$, which was as much three times as that of pure $\mathrm{Mn}_{3} \mathrm{O}_{4}$ samples. ${ }^{133}$ Besides carbon, surface modification with oxides, solid electrolytes and other compounds has been also proved to be effective for improving the electrochemical performance of metal oxide anodes.

$\mathrm{SnO}_{2}$ anode, possessing a high theoretical capacity of 782 $\mathrm{mA} \mathrm{h} \mathrm{g}{ }^{-1}$, however, has a large volume expansion of $\sim 300 \%$, which would result in pulverization and deterioration of the active materials during cycling. Recently, Zhu et al. ${ }^{\mathbf{1 3 4}}$ reported hierarchically porous $\mathrm{TiO}_{2}$ nanotube@ $\mathrm{SnO}_{2}$ nanoflake core/ branch arrays as the LIB electrode, which were synthesized with the ALD process and sacrificial $\mathrm{Co}_{2}(\mathrm{OH})_{2} \mathrm{CO}_{3}$ nanorod template. The hydrothermally grown $\mathrm{SnO}_{2}$ were intimately connected with the vertical-standing $\mathrm{TiO}_{2}$ nanotubes, resembling a forest on the nanoscale (Fig. 9). The spaces between $\mathrm{SnO}_{2}$ nanoflakes could buffer the volume expansion and also assured full access by $\mathrm{Li}^{+}$. The core/branch material exhibited a specific discharge capacity of $498 \mathrm{~mA} \mathrm{~h} \mathrm{~g}^{-1}$ at $3.2 \mathrm{~A} \mathrm{~g}^{-1}$. When

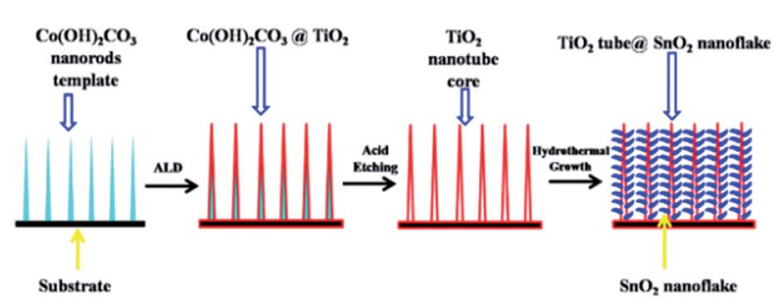

Fig. 9 Schematics of the fabrication process of $\mathrm{TiO}_{2}$ nanotubea $\mathrm{SnO}_{2}$ nanoflake core-branch nanostructures. Reproduced with permission from ref. 134, copyright 2014, Elsevier. the current density was set back to $0.2 \mathrm{~A} \mathrm{~g}^{-1}$ after 50 cycles, the loss of discharge capacity of the core/branch electrode was about $200 \mathrm{~mA} \mathrm{~h} \mathrm{~g}^{-1}$. For the commercial powder, the capacity dropped to near zero when the current density increased above $0.8 \mathrm{~A} \mathrm{~g}^{-1}$. The results indicated that the outer $\mathrm{TiO}_{2}$ may block or retard the direct access of $\mathrm{Li}^{+}$to $\mathrm{SnO}_{2}$ that was supposed to be the main capacity contributor. Meanwhile, $\mathrm{SnO}_{2}$ was released outside of the core/shell structure to assure a direct contact with $\mathrm{Li}^{+}$, in order to achieve large contact area between $\mathrm{SnO}_{2}$ and the electrolyte. Other works aiming at protecting $\mathrm{SnO}_{2}$ from collapse by enwrapping $\mathrm{SnO}_{2}$ inside $\mathrm{TiO}_{2}$ have been also reported. ${ }^{135-137}$

A $\mathrm{ZnO}$ nanorod anode was coated with a $\sim 11 \mathrm{~nm} \mathrm{TiO}_{2}$ layer by ALD. An increased reversible capacity of the coated anode could be observed with $447 \mathrm{~mA} \mathrm{~h}^{-1}$ compared to $358 \mathrm{~mA} \mathrm{~h}^{-1}$ for the uncoated one. ${ }^{138}$ The thin $\mathrm{TiO}_{2}$ layer could not only sustain the mechanical integrity of $\mathrm{ZnO}$ nanorods, but also acted as an "artificial" SEI reducing the degree of reactions between $\mathrm{ZnO}$ and the electrolyte, and thereby improving the cycle stability. It was demonstrated that excellently structural stability and semiconducting nature of $\mathrm{TiO}_{2}$ materials made it a suitable backbone or protective layer for other metal oxides through smart hybridization. An effective strategy to overcome the degradation of $\mathrm{MoO}_{3}$ nanorod anodes at high-rate cycling was achieved by $\mathrm{HfO}_{2}$ surface coating using ALD. At $1.5 \mathrm{~A} \mathrm{~g}^{-1}$, the specific capacity of $\mathrm{HfO}_{2}$-coated $\mathrm{MoO}_{3}$ electrodes $(657 \mathrm{~mA} \mathrm{~h}$ $\mathrm{g}^{-1}$ ) was much higher than that of bare $\mathrm{MoO}_{3}$ electrodes (460 $\mathrm{mA} \mathrm{h} \mathrm{g}^{-1}$ ) after 50 cycles. Furthermore, they observed that $\mathrm{HfO}_{2}$ coated $\mathrm{MoO}_{3}$ electrodes tended to stabilize faster than bare $\mathrm{MoO}_{3}$ electrodes because nanoscale $\mathrm{HfO}_{2}$ layer prevented structural degradation of $\mathrm{MoO}_{3}$ nanorods. ${ }^{139}$

Of particular interest, Xu et al. ${ }^{140}$ employed a sulfur-assisted decomposition process to create agglomerates of large (200-500 $\mathrm{nm}$ ) yet highly nanoporous $3 \mathrm{D} \mathrm{MoO}_{2}$ single crystals partially covered with a few atomic layers of $\mathrm{MoS}_{2}$ (" $\mathrm{MoS}_{2} / \mathrm{MoO}_{2}$ nanonetworks"). As a highly reactive species toward Mo, S would disrupt the orderly growth of largely and fully dense $\mathrm{MoO}_{2}$ crystallites, rather promote highly porous nanostructures. Meanwhile, $\mathrm{MoS}_{2}$ was also a highly active electrode materials, which meant that the formation of any secondary sulfide phase would also contribute to the overall capacity. At $100 \mathrm{~mA} \mathrm{~g}^{-1}$, the $\mathrm{MoS}_{2} / \mathrm{MoO}_{2}$ nanonetworks exhibited a reversible discharge specific capacity of $1233 \mathrm{~mA} \mathrm{~h} \mathrm{~g}^{-1}$, with only $5 \%$ degradation after 80 cycles. Moreover, at fast discharging rates of 0.2 and 0.5 $\mathrm{A} \mathrm{g}^{-1}$, the capacities were 1158 and $826 \mathrm{~mA} \mathrm{~h} \mathrm{~g}^{-1}$, respectively. In addition, solid electrolytes have been also used as protective coatings for metal oxide anodes. Lithium phosphorus oxynitride (LiPON) as a nanocladding layer was successfully coated on a 3D MWCNT@RuO ${ }_{2}$ electrode by means of ALD. The $17 \mathrm{~nm}$ ALD LiPON layer minimized parasitic SEI formation, provided facile ion transport through the LiPON solid electrolyte, and constrained electrode nanostructure. Without LiPON protection, the MWCNT@RuO $\mathrm{R}_{2}$ electrode lost capacity with cycling, retaining only $55 \%$ of the second discharge capacity after 20

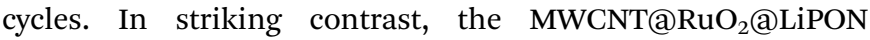
retained $>95 \%$ of the second cycle capacity after 50 cycles. Such favorable capacity retention is unusual for a conversion 
electrode, where lithiation involves insertion of $4 \mathrm{Li}^{+}$per transition metal, significant volume expansion, and chemical/ structural transformation of materials and phases. ${ }^{141}$

\subsection{Surface coatings of Li-rich layered oxide cathodes}

Li-rich layered oxides, $x \mathrm{Li}_{2} \mathrm{MnO}_{3} \cdot(1-x) \mathrm{LiMO}_{2}(\mathrm{M}=\mathrm{Mn}$, Co, $\mathrm{Ni}$ ), have drawn extensive attention recently owing to their larger specific capacity of over $250 \mathrm{~mA} \mathrm{~h} \mathrm{~g}{ }^{-1} \cdot{ }^{142}$ However, sluggish reaction kinetics resulted from intrinsic low electronic conductivity and slow $\mathrm{Li}^{+}$diffusion due to the occupancy of the excess $\mathrm{Li}^{+}$in the transition metal layer, blocking the flow of electrons and diffusion of $\mathrm{Li}^{+}$in the Li-rich layered oxides. ${ }^{143,144}$ To improve its electrochemical characteristics, different surface coatings with oxides $\left(\mathrm{Al}_{2} \mathrm{O}_{3},{ }^{145} \mathrm{Li}_{2} \mathrm{SiO}_{3},{ }^{146} \mathrm{Li}_{2} \mathrm{ZrO}_{3}\right.$ (ref. 147) and $\mathrm{CeO}_{2}$ (ref. 148)), fluorite $\left(\mathrm{AlF}_{3}\right.$ (ref. 149)), phosphates ${ }^{150}$ and metallic $\mathrm{Al}^{151}$ have been reported to improve the electrochemical performance of Li-rich layered materials. However, the surface modification has not been optimized, and yet cannot achieve high capacity and remarkable rate capability and enhanced cycle performance simultaneously. New effective way of surface modification would be anticipated.

Recently, Li-rich $\mathrm{Li}_{1.2} \mathrm{Mn}_{0.525} \mathrm{Ni}_{0.175} \mathrm{Co}_{0.1} \mathrm{O}_{2}$ (Li-rich NMC) material was coated by a nanometer layer coating of a $\mathrm{Li}^{+}$conducting solid electrolyte, LiPON, by RF-magnetron sputtering method. ${ }^{152}$ The LiPON coated Li-rich NMC composite electrode showed stable reversible capacities of $>275 \mathrm{~mA} \mathrm{~h} \mathrm{~g}{ }^{-1}$ when cycled to $4.9 \mathrm{~V}$ over 300 cycles, and showed improvements in the rate performance compared to the uncoated ones at current rates of $5 \mathrm{C}$ and higher. Increasing the thickness of the LiPON layer would lead to capacity fade due to increasing electronic resistance.

The active $\mathrm{Li}_{2} \mathrm{MnO}_{3}$ in the layered material $\mathrm{Li}_{1.2} \mathrm{Ni}_{0.13^{-}}$ $\mathrm{Mn}_{0.54} \mathrm{Co}_{0.13} \mathrm{O}_{2}$ reacted with hydrazine vapor that was employed to extract $\mathrm{Li}^{+}$from the surface region. Thus, a Li-deficient and proton-incorporated layer was formed on the surface. The removal of the incorporated protons and migration of transition metal ions from the transition metal layer into the Li layer at $300{ }^{\circ} \mathrm{C}$ resulted in a spinel $\mathrm{Li}_{1-x} \mathrm{M}_{2} \mathrm{O}_{4}$ phase on the surface of the layered material. Compared to the pristine material, the surface modified sample annealed at $300^{\circ} \mathrm{C}$ delivered a larger initial discharge capacity of $296 \mathrm{~mA} \mathrm{~h} \mathrm{~g}^{-1}$ with a CE of $89.5 \%$ and a better rate performance $\left(192 \mathrm{~mA} \mathrm{~h} \mathrm{~g}^{-1}\right.$ at $\left.0.4 \mathrm{~A} \mathrm{~g}^{-1}\right) .{ }^{153}$

Olivine-type $\mathrm{LiMnPO}_{4}$ is regarded as one of the most promising electroactive materials with a high charge potential, in analogy to that of Li-rich layered oxides. The surface modification via a thin amorphous $\mathrm{Li}-\mathrm{Mn}-\mathrm{PO}_{4}$ with a thickness of 5$7 \mathrm{~nm}$ was introduced onto Li-rich layered oxide $\mathrm{Li}\left(\mathrm{Li}_{0.17} \mathrm{Ni}_{0.25^{-}}\right.$ $\left.\mathrm{Mn}_{0.58}\right) \mathrm{O}_{2}{ }^{154}$ leading to enhanced performance. With increasing calcination temperature after the surface coating, a strong interaction could be induced on the interface between the amorphous layer and the top surface of $\mathrm{Li}\left(\mathrm{Li}_{0.17} \mathrm{Ni}_{0.25} \mathrm{Mn}_{0.58}\right)$ $\mathrm{O}_{2}$ grains. The initial discharge capacity of the as-prepared sample was $261 \mathrm{~mA} \mathrm{~h} \mathrm{~g}^{-1}$ with $\mathrm{CE}$ of $80.7 \%$. For the coated sample after calcination at $400^{\circ} \mathrm{C}$, the initial discharge capacity and $\mathrm{CE}$ were $293 \mathrm{~mA} \mathrm{~h} \mathrm{~g}^{-1}$ and $85.5 \%$, respectively. The maximum discharge capacity of the as-prepared
$\mathrm{Li}\left(\mathrm{Li}_{0.17} \mathrm{Ni}_{0.25} \mathrm{Mn}_{0.58}\right) \mathrm{O}_{2}$ was $97.9 \mathrm{~mA} \mathrm{~h} \mathrm{~g}{ }^{-1}$ at $5 \mathrm{C}$ rate $(1.5 \mathrm{~A}$ $\left.\mathrm{g}^{-1}\right)$. For $\mathrm{Li}-\mathrm{Mn}-\mathrm{PO}_{4}$-coated samples after calcination at 400 and $500{ }^{\circ} \mathrm{C}$, the maximum discharge capacities at $5 \mathrm{C}$ were 158.8 and $140.5 \mathrm{~mA} \mathrm{~h} \mathrm{~g}^{-1}$, respectively.

Instead of classic physical-adsorption/deposition techniques, Guo et al. ${ }^{155}$ proposed a novel chemical-adsorption strategy to synthesize double-shell modified Li-rich layered cathodes with enhanced mass transfer kinetics. Based on experimental measurement and first-principles calculation, $\mathrm{MoO}_{2} \mathrm{~S}_{2}$ ions were proved to join the layered phase via chemical bonding. Specifically, the Mo-O or Mo-S bonds could flexibly rotate to bond with the cations in the layered phase, leading to the good compatibility between the thiomolybdate adsorption layer and layered cathode. The double-shell modified sample delivered an enhanced discharge capacity almost twice as much as that of the unmodified one at $1 \mathrm{~A} \mathrm{~g}^{-1}$ after 100 cycles, demonstrating the superiority of the surface modification based on chemical adsorption. ${ }^{155}$

The surface nitridation was introduced into a Li-rich layered oxide $\mathrm{Li}\left(\mathrm{Li}_{0.17} \mathrm{Ni}_{0.25} \mathrm{Mn}_{0.58}\right)$ via heating at $400{ }^{\circ} \mathrm{C}$ in the ammonia atmosphere. It was demonstrated that a trace amount of nitrogen existed on the surface of the active material after the nitridation treatment. After 60 cycles, the discharge capacity of the nitrided sample still retained at $256 \mathrm{~mA} \mathrm{~h}^{-1}$, showing good capacity retention. On the contrary, the discharge capacity of bare sample quickly decreased from 224 to $141 \mathrm{~mA} \mathrm{~h} \mathrm{~g}^{-1}$ after 57 cycles. ${ }^{156}$ Therefore, the surface nitridation was an effective way to improve the electrochemical performance of the electroactive materials for LIBs. The same strategy adapted in this work could be helpful to explore and develop desired cathode materials for new generation LIBs.

Wu et al. ${ }^{157}$ proposed a biomimetic design and versatile synthesis strategy of ultrathin spinel membrane-encapsulated layered Li-rich cathode material. A polymer dispersant (polyvinylpyrrolidone) was initially dispersed on the pristine layered Li-rich materials $\mathrm{Li}_{1.2} \mathrm{Mn}_{0.6} \mathrm{Ni}_{0.2} \mathrm{O}_{2}$ to assist the subsequent homogeneous decoration of the manganese salt. Eventually, spinel $\mathrm{Li}_{1+x} \mathrm{Mn}_{2} \mathrm{O}_{4}$ membrane could be yielded on the surface after heat treatment, due to the ion diffusion from the bulk. Therefore, surface modification with an ultrathin nanolayer of spinel $\mathrm{Li}_{1+x} \mathrm{Mn}_{2} \mathrm{O}_{4}$ as a "membrane" encapsulating on a layered Li-rich cathode were explored as shown in Fig. 10a. TEM image of the ultrathin spinel membrane encapsulated-layered Li-rich
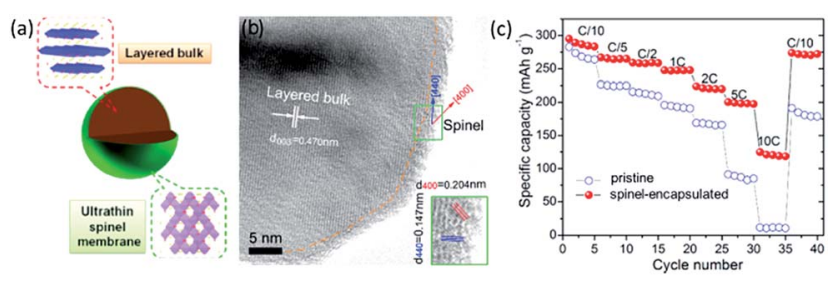

Fig. 10 (a) Schematic structure, and (b) TEM images for spinelencapsulated cathode material. (c) Rate performance of the pristine and spinel-encapsulated samples, at a fixed charge rate of $\mathrm{C} / 10$ and different discharge rates. Reproduced with permission from ref. 157, copyright 2014, American Chemical Society. 
cathode (Fig. 10b) showed the existence of a homogeneously ultrathin layer. As shown in Fig. 10c, the pristine sample showed a poor rate capability, a dramatic capacity drop with the increasing of C-rate, and nearly no capacity was obtained at a $10 \mathrm{C}$ rate. When cycling back to C/10 rate, a capacity of only 190 $\mathrm{mA} \mathrm{h} \mathrm{g}^{-1}$ was maintained. On the contrary, the spinelencapsulated sample yielded maximal discharge capacities of $247.9 \mathrm{~mA} \mathrm{~h} \mathrm{~g}^{-1}, 223.8 \mathrm{~mA} \mathrm{~h} \mathrm{~g}^{-1}$, and $200.1 \mathrm{~mA} \mathrm{~h} \mathrm{~g}^{-1}$ at 1C, 2C, and 5C rates, respectively. Surprisingly, it delivered a high capacity of $124.8 \mathrm{~mA} \mathrm{~h} \mathrm{~g}^{-1}$ even at $10 \mathrm{C}$, over $40 \%$ of the capacity at $\mathrm{C} / 10$ (inset of Fig. 10c). It even maintained $275 \mathrm{~mA} \mathrm{~h} \mathrm{~g}^{-1}$ when returned to the $\mathrm{C} / 10$ rate. Hence, the spinel-encapsulated material combined advantages of high capacity from the bulk layered Li-rich cathode and high rate capability from the spinel membrane. It was demonstrated that this high $\mathrm{Li}^{+}$conductive membrane could rapidly transport $\mathrm{Li}^{+}$between the electrolytes and the layered bulk as a " $\mathrm{Li}^{+}$pump".

Xia et al. ${ }^{158}$ fabricated a novel Layered@Spinel@Carbon (LSC) heterostructured cathode material via a carbothermal reduction route. A spinel phase in situ formed along the layered bulk/carbon interface with the assistance of carbon reduction, which expedited $\mathrm{Li}^{+}$(de)intercalation between electrolyte and Li-rich layered cores. Thus, the LSC material comprised a core of Li-rich layered oxide $(R \overline{3} m)$, a spinel phase $(F d \overline{3} m)$ interlayer and a carbon nanocoating (Fig. 11). The rate capability was galvanostatically investigated to $4.8 \mathrm{~V}$ from 0.2 to 20C. When discharged at 2C, the LSC sample delivered a higher discharge capacity of $273.2 \mathrm{~mA} \mathrm{~h} \mathrm{~g}^{-1}$, whereas the pristine sample showed a lower capacity of $187 \mathrm{~mA} \mathrm{~h} \mathrm{~g}^{-1}$. By increasing the discharge rate to $10 \mathrm{C}$, more surprisingly, the LSC sample exhibited a discharge capacity of $234 \mathrm{~mA} \mathrm{~h} \mathrm{~g}{ }^{-1}$, which was approximate 3.2 times that of the pristine sample. Even for ultra-high discharge rates of 20C, nearly no discharge capacity was observed for the pristine sample, while the LSC sample achieved a reversible discharge capacity of more than $120 \mathrm{~mA} \mathrm{~h}^{-1}$. They illustrated that the unique structure of the LSC cathode materials combined the advantages of the high capacity Li-rich layered structure, 3D fast $\mathrm{Li}^{+}$diffusion channels of the spinel structure, and the high conductivity of the carbon coating.

Chen et al. ${ }^{159}$ proposed and constructed a spinel-structure skin and ferric oxide islands on the surface of layered Li-rich cathode materials through a facile wet chemical method. The modified sample displayed a high discharge capacity of 166

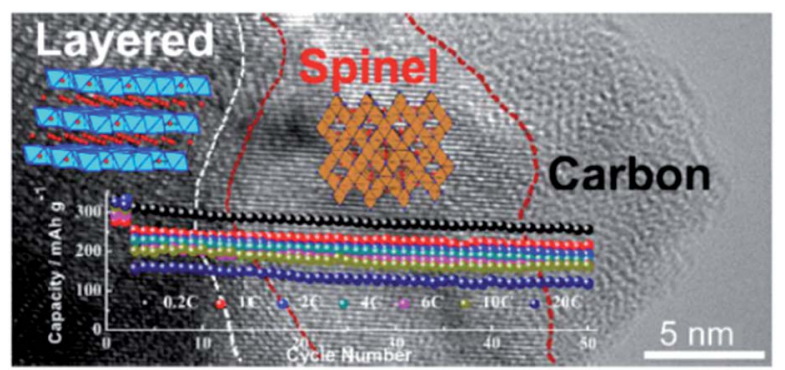

Fig. 11 A Li-rich LSC heterostructured cathode material, comprised of a Li-rich layered core, a spinel interlayer, and a carbon nanocoating. Reproduced with permission. ${ }^{158}$
$\mathrm{mA} \mathrm{h} \mathrm{g} \mathrm{g}^{-1}$ at $1.25 \mathrm{~A} \mathrm{~g}^{-1}$, and more stable capacity retention of $84.0 \%$ after 50 cycles at $\mathrm{C} / 10$, in contrast to $60.6 \%$ for pristine material. Their surface modification strategy, combining with the advantages of spinel structure and chemically inert ferric oxide nanoparticles, realized the layered Li-rich cathodes with surface construction of fast ion diffusing capability as well as robust electrolyte corroding durability. This design is able to modify the subsurface structure and surface environment of layered lithium-metal oxides particles, simultaneously.

\subsection{Surface modification for high voltage spinel cathodes}

Spinel $\mathrm{LiMn}_{2-x} \mathrm{M}_{x} \mathrm{O}_{4}(\mathrm{M}=\mathrm{Ni}, \mathrm{Cr}, \mathrm{Cu}, \mathrm{Fe}$, and Co) materials generally have a high voltage plateau at $>4.5 \mathrm{~V}$ and deliver a high capacity in the range of $130-150 \mathrm{~mA} \mathrm{~h} \mathrm{~g}^{-1}$. However, these materials suffer from structural instability, electrolyte decomposition, dissolution of $\mathrm{Mn}$ and $\mathrm{Ni}$, and Jahn-Teller distortion, particularly under high voltage and elevated temperatures. Previous reports on surface coatings, such as $\mathrm{ZnO},{ }^{160} \mathrm{TiO}_{2},{ }^{161}$ $\mathrm{SiO}_{2},{ }^{162} \mathrm{Y}_{2} \mathrm{O}_{3},{ }^{163} \mathrm{CuO},{ }^{164}$ and $\mathrm{V}_{2} \mathrm{O}_{5},{ }^{165}$ have indicated the improvement over the electrochemical performance of the cathode materials. Unfortunately, the high-voltage spinels still undergo poor rate performances, large capacity fade, or discharge voltage decay because of low conductivity or stability issue of these oxide materials. Efficient route needs be designed to further enhance their cyclic properties for practical applications of the high-voltage spinel materials in LIBs.

Recently, Gao et al. ${ }^{\mathbf{1 6 6}}$ explored conductive PPy-coated $\mathrm{LiNi}_{0.5} \mathrm{Mn}_{1.5} \mathrm{O}_{4}$ (LNMO) cathodes for LIBs, considering the electrical conductivity of PPy could reach a few tenths of $\mathrm{S} \mathrm{cm}^{-1}$. They compared the cycling performances of bare LNMO and PPy-coated LNMO at $1 \mathrm{C}$ and $55^{\circ} \mathrm{C}$ (Fig. 12a and b). The bare LNMO delivered a discharge capacity of $94.5 \mathrm{~mA} \mathrm{~h} \mathrm{~g}^{-1}$ and exhibited capacity retention of only $81.4 \%$ after 100 cycles. While the LNMO-5 wt\% PPy still retained a reversible capacity of $105.2 \mathrm{~mA} \mathrm{~h} \mathrm{~g}^{-1}$, corresponding to a retention of $91 \%$ after 100 cycles. The CEs of all the cells with PPy coating could reach $92 \%$ after 5 cycles, while that for bare LNMO was only around $90 \%$. They also demonstrated (Fig. 12c) that a uniform PPy coating on the surface of the LNMO could not only act as an ion-conductive layer, but also suppress the decomposition of $\mathrm{Mn}$ and $\mathrm{Ni}$ at elevated temperatures.

$\mathrm{FeF}_{3}$-coated $\mathrm{LiMn}_{2} \mathrm{O}_{4}$ materials were synthesized by chemical deposition method. The $\mathrm{FeF}_{3}$-coated $\mathrm{LiMn}_{2} \mathrm{O}_{4}$ electrodes displayed enhanced cycling stabilities compared with that of pristine $\mathrm{LiMn}_{2} \mathrm{O}_{4}$. Especially, the $5 \mathrm{wt} \% \mathrm{FeF}_{3}$-coated $\mathrm{LiMn}_{2} \mathrm{O}_{4}$ achieved the capacity retentions of $68.2 \%$ after 200 cycles at $25{ }^{\circ} \mathrm{C}$, and $61.5 \%$ after 100 cycles at $55{ }^{\circ} \mathrm{C}$, which were much better than those of the pristine materials (49.8\% and $40.2 \%)$. They explained the effect of $\mathrm{FeF}_{3}$ surface coating including: (1) preventing the dissolution of $\mathrm{Mn}$ ions; (2) suppressing the impedance increase in repeated cycling; and (3) improving thermal stability of electrode material. ${ }^{167}$ Similarly, Wu et al. ${ }^{\mathbf{1 6 8}}$ modified spinel LNMO cathode material synthesized by a solgel method with thin $\mathrm{AlF}_{3}$ coatings through simple chemical deposition. The $\mathrm{AlF}_{3}$-coated LNMO materials displayed enhanced cycling stabilities. The $1 \mathrm{wt} \% \mathrm{AlF}_{3}$-coated LNMO 

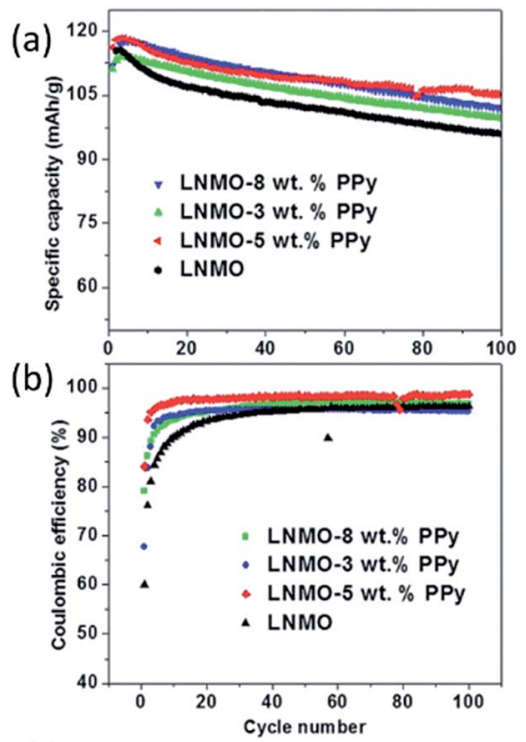

(c)

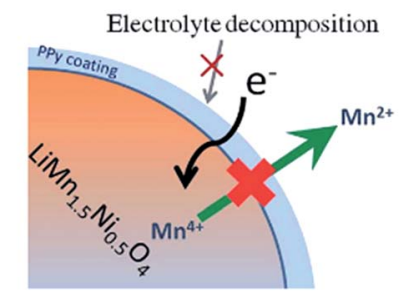

Fig. 12 Cycling performance of LNMO, LNMO-3 wt\% PPy, LNMO-5 wt $\%$, and LNMO- 8 wt\% PPy at $1 \mathrm{C}$ and $55^{\circ} \mathrm{C}$ : (a) specific capacity, and (b) CE. (c) Illustration of how the PPy layer acts as a conductive and protective layer to suppress the dissolution of $\mathrm{Mn}$, as well as the unwanted electrolyte decomposition at elevated temperature. Reproduced with permission. ${ }^{166}$

showed improved reversibility with capacity retention of $93.6 \%$ after 50 cycles, which was much higher than that of the pristine material $(77.6 \%)$.

$\mathrm{AlPO}_{4}$-coated LNMO was prepared by a sol-gel method with citric acid. ${ }^{169}$ The thickness of the coated layers of $\mathrm{LNMO} \mathrm{AlPO}_{4}$ ( $1 \mathrm{wt} \%$ ) was determined to be about $15 \mathrm{~nm}$ by AES with sputtering. It was found that the surface and charge-transfer resistances of the modified electrode ( 4.3 and $20.7 \Omega$ ) were much lower than those of the pristine sample (5.9 and 52.8 $\Omega$ ), and the $\mathrm{Li}^{+}$diffusion rate of the modified electrode was also significantly enhanced. As a result, $\mathrm{AlPO}_{4}$ could be employed as a coating material to improve the thermal stability and electrochemical performance of LNMO cathodes.

The $\mathrm{Li}_{2} \mathrm{ZrO}_{3}$-coated spherical spinel $\mathrm{LiMn}_{2} \mathrm{O}_{4}$ samples were synthesized via sol-gel method. ${ }^{170}$ It was found that the $\mathrm{Li}_{2} \mathrm{ZrO}_{3}$ coating uniformly deposited on the surface of the spherical spinel $\mathrm{LiMn}_{2} \mathrm{O}_{4}$ with a thickness of $3 \mathrm{~nm}$. The electrochemical results indicated that the $3 \mathrm{wt} \% \mathrm{Li}_{2} \mathrm{ZrO}_{3}$ coated $\mathrm{LiMn}_{2} \mathrm{O}_{4}$ sample possessed excellent cycling performance with $99.0 \%$ and $90.2 \%$ capacity retention after 100 cycles at $1 \mathrm{C}$ at $25{ }^{\circ} \mathrm{C}$ and $55{ }^{\circ} \mathrm{C}$, compared to $89.9 \%$ and $58.0 \%$ of uncoated spinel $\mathrm{LiMn}_{2} \mathrm{O}_{4}$. It was demonstrated that $\mathrm{Li}_{2} \mathrm{ZrO}_{3}$ as a ceramic material not only had excellent stability and chemical inert towards HF erosion, but also the structure of $\mathrm{Li}_{2} \mathrm{ZrO}_{3}$ was compatible for $\mathrm{Li}^{+}$ transportation.
Spinel $\mathrm{LiMn}_{2} \mathrm{O}_{4}$ and multi-doped spinel $\mathrm{LiMn}_{1.9} \mathrm{Co}_{0.025^{-}}$ $\mathrm{Cr}_{0.025} \mathrm{Ni}_{0.025} \mathrm{Fe}_{0.025} \mathrm{O}_{4}$ (LMCCNF) were synthesized by the glycine-nitrate method and coated with Li borosilicate (LBS) via the simple solution method in order to enhance the electrochemical performance at room temperature. ${ }^{171}$ Compared with the uncoated samples, the LBS-coated LMCCNF sample exhibited an improved cycling stability. The capacity losses in the first 70 cycles between 3.5 and $4.5 \mathrm{~V}$ decreased significantly from $25.4 \%, 16.1 \%$ to $11 \%$ for uncoated $\mathrm{LiMn}_{2} \mathrm{O}_{4}$, LMCCNF and LBS coated $\mathrm{LiMn}_{2} \mathrm{O}_{4}$, respectively. The LBS-coated LMCCNF showed $8.5 \%$ capacity loss of the initial discharge capacity.

A novel spinel cathode material with an average composition of $\mathrm{LiMn}_{1.912} \mathrm{Ni}_{0.072} \mathrm{Co}_{0.016} \mathrm{O}_{4}$, in which the $\mathrm{LiMn}_{2} \mathrm{O}_{4}$ core material was completely encapsulated by a stable spinel structure concentration-gradient shell (CGS), was successfully synthesized via co-precipitation process. ${ }^{172}$ This arterial consisted of a core of $\mathrm{LiMn}_{2} \mathrm{O}_{4}$ and a CGS with decreasing $\mathrm{Mn}$ concentration and increasing $\mathrm{Ni}$ and Co concentration toward the particle surface. It was found that the electrochemical properties of the $\mathrm{LiMn}_{1.912} \mathrm{Ni}_{0.072} \mathrm{Co}_{0.016} \mathrm{O}_{4}$ material were superior to those of the alone $\mathrm{LiMn}_{2} \mathrm{O}_{4}$ core material. Besides, the core-CGS $\mathrm{LiMn}_{1.912^{-}}$ $\mathrm{Ni}_{0.072} \mathrm{Co}_{0.016} \mathrm{O}_{4}$ sample delivered a discharge capacity of 118 $\mathrm{mA} \mathrm{h}{ }^{-1}$ between 3.0 and $4.4 \mathrm{Vvs} \mathrm{Li}^{+} / \mathrm{Li}$ with a retention of $96 \%$ over 200 cycles at $1 \mathrm{C}\left(148 \mathrm{~mA} \mathrm{~g}^{-1}\right)$ and $55^{\circ} \mathrm{C}$. It could still deliver a high discharge capacity of over $110 \mathrm{~mA} \mathrm{~h} \mathrm{~g}^{-1}$ even at $5 \mathrm{C}$.

\subsection{Nanostructured films on sulfur based cathodes}

World-wide attention has been gained to sulfur and metal sulfides as promising cathode materials for LIBs due to their high theoretical specific capacity (1672 $\mathrm{mA} \mathrm{h}^{-1}$ for S, and 1166 $\mathrm{mA} \mathrm{h} \mathrm{g}^{-1}$ for $\mathrm{Li}_{2} \mathrm{~S}$ ). However, there are two major disadvantages that limit practical applications of the S-based cathodes. One is associated with uncontrolled dissolution and loss of intermediate lithium polysulphide $\left(\mathrm{Li}_{2} \mathrm{~S}_{n}, n=4-8\right)$ species into the electrolyte, leading to fast capacity decay and low CE. The other one is the large volume change during charge-discharge process, leading to pulverization and inactivity of cathode materials and thus poor cycling life and rate capability. Typical strategy to address these challenges is to encapsulate S-based materials with electronically conductive carbon-based materials. ${ }^{173-176}$ Although such approaches have shown many progresses with improved electrochemical performance for the $\mathrm{S}$ based electrodes, electrochemical reversibility and rate capacity of the modified S-based materials are still unsatisfactory. It is considered that the nonpolar nature of carbon-based materials leads to weak interaction with polar S-containing species, ${ }^{177}$ which greatly reduces their ability to bind and confine these species within the carbon-based shell during cycling. Therefore, there is an urgent need in new modification routes for S-based cathodes that can achieve both high conductivity and strong binding with S-based materials simultaneously.

Recently, Seh et al. ${ }^{177}$ encapsulated $\mathrm{Li}_{2} \mathrm{~S}$ cathodes by using $2 \mathrm{D}$ layered transition metal disulphides that possessed a combination of high conductivity and strong binding with $\mathrm{Li}_{2} \mathrm{~S} / \mathrm{Li}_{2} \mathrm{~S}_{n}$ species. Using $\mathrm{TiS}_{2}$ with a thickness of $\sim 20 \mathrm{~nm}$ as an 
encapsulation material, the $\mathrm{Li}_{2} \mathrm{~S} @ \mathrm{TiS}_{2}$ cathodes showed stable cycling performance at $\mathrm{C} / 2$ over 400 cycles. Relative to the initial specific capacity of $666 \mathrm{~mA} \mathrm{~h} \mathrm{Li}_{2} \mathrm{~s}^{-1}\left(956 \mathrm{~mA} \mathrm{~h} \mathrm{~g}^{-1}\right)$ at $\mathrm{C} / 2$, the cells retained $77 \%$ of their capacity after 400 cycles (i.e., a capacity decay of $0.058 \%$ per cycle). The average CE was $98 \%$. Moreover, they also demonstrated a high specific capacity of $503 \mathrm{~mA} \mathrm{~h} \mathrm{~g}_{\mathrm{Li}_{2} \mathrm{~S}}{ }^{-1}$ at $4 \mathrm{C}$ as well as a high areal capacity of $3 \mathrm{~mA} \mathrm{~h}$ $\mathrm{cm}^{-2}$ under high mass-loading conditions $\left(5.3 \mathrm{mg}_{\mathrm{Li}_{2} \mathrm{~S}} \mathrm{~cm}^{-2}\right)$. The improvement of electrochemical performance should be related to the facts that $\mathrm{TiS}_{2}$ possessed high conductivity, and polar Ti-S groups could potentially interact strongly with $\mathrm{Li}_{2} \mathrm{~S} /$ $\mathrm{Li}_{2} \mathrm{~S}_{n}$ species. By using $\mathrm{ZrS}_{2}$ and $\mathrm{VS}_{2}$ as further examples, this work open up the new concept of using $2 \mathrm{D}$ layered transition metal disulphides as a general class of effective encapsulation materials for achieving high performance in $\mathrm{Li}_{2} \mathrm{~S}$ cathodes.

In addition, Tan et al. ${ }^{178}$ reported a facile and novel method to prepare pyrite nano- $\mathrm{FeS}_{2}$ wrapped in an $\mathrm{N}$-graphene framework (core-shell nano-FeS $\mathrm{F}_{2} @ \mathrm{~N}$-graphene). The N-doped graphene as shell had optimized electronic conductivity, which made the $\mathrm{FeS}_{2}$ nanoparticles possess more fast charge transfer channels. As a result, the cells with $\mathrm{FeS}_{2} @ \mathrm{~N}$-graphene cathode exhibited a high specific energy ( $950 \mathrm{~W} \mathrm{~h} \mathrm{~kg}{ }^{-1}$ at $\left.0.1 \mathrm{~A} \mathrm{~g}^{-1}\right)$, high specific power $\left(543 \mathrm{~W} \mathrm{~h} \mathrm{~kg}^{-1}\right.$ at $2 \mathrm{~A} \mathrm{~g}^{-1}$ ) than the commercial cathodes, as well as stable cycling performance $\left(\sim 600 \mathrm{~W} \mathrm{~h} \mathrm{~kg}^{-1}\right.$ at $0.75 \mathrm{~kW} \mathrm{~g}^{-1}$ after 400 cycles). Compared to the reported $\mathrm{LiCoO}_{2}\left(504 \mathrm{~W} \mathrm{~h} \mathrm{~kg}^{-1}\right), \mathrm{LiNi}_{0.5} \mathrm{Co}_{0.2} \mathrm{Mn}_{0.3} \mathrm{O}_{2}\left(530 \mathrm{~W} \mathrm{~h} \mathrm{~kg}{ }^{-1}\right.$ at 0.5 $\left.\mathrm{A} \mathrm{g}^{-1}\right), \mathrm{LiFePO}_{4}\left(450 \mathrm{~W} \mathrm{~h} \mathrm{~kg}^{-1}\right.$ at $\left.0.5 \mathrm{~A} \mathrm{~g}^{-1}\right)$ and $\mathrm{LiMn}_{2} \mathrm{O}_{4}$, (390 $\mathrm{W} \mathrm{h} \mathrm{kg}{ }^{-1}$ at $0.5 \mathrm{~A} \mathrm{~g}^{-1}$ ), the $\mathrm{FeS}_{2} @ \mathrm{~N}$-graphene showed a potential cathode material for the next generation LIBs.

Li et al. ${ }^{179}$ developed a feasible strategy to deposit doublelayered films containing conducting polymer of PPy and carbon nanofiber (CNF) on NiS to form high-performance freestanding LIB cathodes. Using the PPy-CNF hybrid films with a high Nis loading of $5.5 \mathrm{mg} \mathrm{cm}^{-2}$ as a cathode, they demonstrated a high discharge capacity of $635 \mathrm{~mA} \mathrm{~h} \mathrm{~g}^{-1}$ at $0.1 \mathrm{~A} \mathrm{~g}^{-1}$ and exceptional areal capacity of $3.03 \mathrm{~mA} \mathrm{~h} \mathrm{~cm}{ }^{-2}$ at $0.7 \mathrm{~mA}$ $\mathrm{cm}^{-2}$ with long cycling life over 700 cycles. It was emphasized that PPy coating maintained the structural integrity and accommodated volumetric change of NiS upon cycling, and also enhanced electronic conduction, while CNF film provided a well mechanical and effectively electrical interconnection in the entire electrode. This work provides new avenues for further improvement by conductive hybrid coatings on NiS cathodes to yield high capacity and long-term stability. This promising design and concept can be extended to other high-capacity cathodes with high volumetric expansion, such as $\mathrm{S}$ and $\mathrm{Li}_{2} \mathrm{~S}$.

Zhu et al. ${ }^{180}$ fabricated an $\mathrm{FeS}_{2}$ @carbon fiber electrode consisting of $\mathrm{FeS}_{2}$ nanoparticles embedded into carbon fibers by electrospinning, the whole $\mathrm{FeS}_{2} @$ @arbon fiber electrode was then coated with a thin layer of $\mathrm{Al}_{2} \mathrm{O}_{3}(\sim 5 \mathrm{~nm})$ by using ALD. It was observed from Fig. 13a that the $\mathrm{Al}_{2} \mathrm{O}_{3}$-coated $\mathrm{FeS}_{2} @$ carbon fiber electrode presented great electrochemical performance in the voltage range of between 1 and $3 \mathrm{~V}\left(v s . \mathrm{Li}^{+} / \mathrm{Li}\right)$. The discharge energy density of the $\mathrm{Al}_{2} \mathrm{O}_{3}$-coated $\mathrm{FeS}_{2}$ @carbon fiber electrode initially reached $1000 \mathrm{~W} \mathrm{~h} \mathrm{~kg}^{-1}$ at electrode level and $\sim 1300$

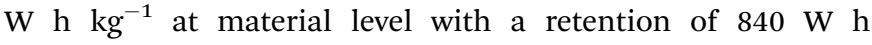
$\mathrm{kg}_{\text {electrode }}{ }^{-1}\left(\sim 1110 \mathrm{~W} \mathrm{~h} \mathrm{~kg}_{\mathrm{Fes}_{2}}{ }^{-1}\right)$ after 100 cycles. They also

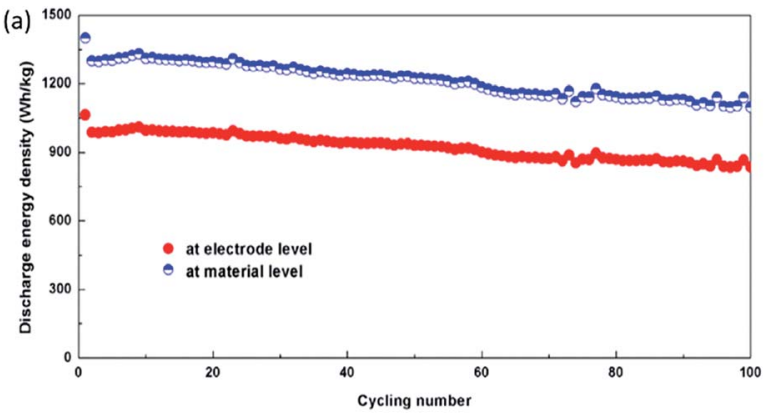

(b)

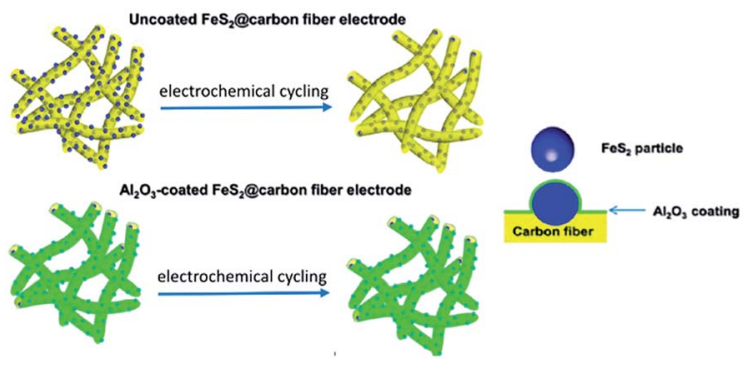

Fig. 13 (a) Cycling stability at material level ( ${\mathrm{W} \mathrm{h} \mathrm{kgeS}_{2}}^{-1}$ ) and electrode level ( $\mathrm{W} \mathrm{h} \mathrm{kg} \mathrm{FeS}_{2}$ electorde ${ }^{-1}$ ) for $\mathrm{Al}_{2} \mathrm{O}_{3}$-coated $\mathrm{FeS}_{2}$ (acarbon fiber electrode; (b) illustration of mechanisms for the enhanced cycling stability by $\mathrm{Al}_{2} \mathrm{O}_{3}$ coating. Reproduced with permission from ref. 180, copyright 2016, American Chemical Society.

illustrated the mechanisms for the enhanced cycling stability by $\mathrm{Al}_{2} \mathrm{O}_{3}$ coating (Fig. 13b). First, it could improve the integrity of electrodes, which should be attributed to the mechanical protection provided by the conformal $\mathrm{Al}_{2} \mathrm{O}_{3}$ coating. Second, the $\mathrm{Al}_{2} \mathrm{O}_{3}$ coating could serve as an artificial barrier to restrain the lithium polysulfides dissolution and mitigate the shuttle effects. Third, upon electrochemical cycling, $\mathrm{AlF}_{3}$ and $\mathrm{LiAlO}_{2}$ with enhanced ionic conductivity would be formed on the top of $\mathrm{Al}_{2} \mathrm{O}_{3}$ coating layer due to the interactions between electrolyte salt and $\mathrm{Al}_{2} \mathrm{O}_{3}$.

\section{New materials and chemistry for Li-based batteries}

Issues such as cost, safety and energy density should be addressed for conventional rechargeable LIBs when they are considered for electric vehicle and smart grid applications. New demonstration using low material cost, facile battery manufacture and flexible cell design offers possibilities that are not easily accessible for traditional materials and setup. This section discusses the recent development in organic electrode materials, novel electrolyte chemistry (high voltage aqueous electrolytes, and dual-ion electrolytes), new electrodes and cell configurations (symmetric electrodes, and semi-solid flow suspension) for Li-based rechargeable batteries. LIBs use typically static transition metal-based inorganic solid state electrode materials and organic solvent-based electrolyte to achieve high operation voltage and broad electrochemical window, respectively. Affordable green energy storage technologies using alternative materials/electrolytes, versatile battery structure are desirable for practical applications. 


\subsection{Organic active materials}

Rechargeable batteries with organic electrode materials are promising in terms of resource availability, cost and sustainability. Physiochemical and electrochemical properties of organic compounds can be altered by modifying their structures. Comprehensive summaries of organic electrode materials for energy storage have been overviewed elsewhere. ${ }^{\mathbf{1 8 1 , 1 8 2}}$ Organic electrode materials can be classified as: organosulfur, radical and carbonyl compounds, polymers and layered materials etc. (Fig. 14a). ${ }^{183}$ Many organic materials show high practical capacities beyond $300 \mathrm{~mA} \mathrm{~h} \mathrm{~g}^{-\mathbf{1}} \cdot \mathbf{. 1 8}^{\mathbf{1 8 4}}$ For instance, benzoquinone has theoretical capacity of $496 \mathrm{~mA} \mathrm{~h} \mathrm{~g}^{-1}$, and can be operated at $2.8 \mathrm{~V}$ with a corresponding energy density up to $1400 \mathrm{~W} \mathrm{~h} \mathrm{~kg}^{-1}$, compared to about $400-500 \mathrm{~W} \mathrm{~h} \mathrm{~kg}^{-1}$ for the common inorganic $\mathrm{LiCoO}_{2}$ and $\mathrm{LiFePO}_{4}$. A carbonyl compound calix[4]quinone $\left(\mathrm{C}_{28} \mathrm{H}_{16} \mathrm{O}_{8}\right.$, theoretical capacity $\left.446 \mathrm{~mA} \mathrm{~h} \mathrm{~g}{ }^{-1}\right)$ has an initial capacity of about $422 \mathrm{~mA} \mathrm{~h} \mathrm{~g}^{-1}$ (Fig. 14b), and can still deliver a capacity of about $380 \mathrm{~mA} \mathrm{~h} \mathrm{~g}^{-1}$ after 100 cycles at $\mathrm{C} / 5$ using a gel polymer electrolyte. ${ }^{184}$ Active organic material such as $\mathrm{Li}_{4} \mathrm{C}_{6} \mathrm{O}_{6}$ containing $\mathrm{C}=\mathrm{O}$ functionalities enables a multiple-electron transfer reaction in a symmetric cell $\mathrm{Li}_{2} \mathrm{C}_{6} \mathrm{O}_{6} / \mathrm{Li}_{6} \mathrm{C}_{6} \mathrm{O}_{6}$ with a good cyclability of about $200 \mathrm{~mA} \mathrm{~h} \mathrm{~g}$ (Fig. 14c). ${ }^{\mathbf{1 8 5}}$

Recently, an all-organic rechargeable battery with aqueous electrolyte with a high charge cutoff voltage of $2.1 \mathrm{~V}$ has been reported. ${ }^{186}$ An aqueous electrolyte containing lithium bis(trifluoromethanesulfonyl)imide (LiTFSI) with a concentration of 21 molarity allows a high redox potential of polytriphenylamine cathode (Fig. 15a), and a low negative potential of 1,4,5,8naphthalenetetracarboxylic dianhydride-derived polyimide (a)
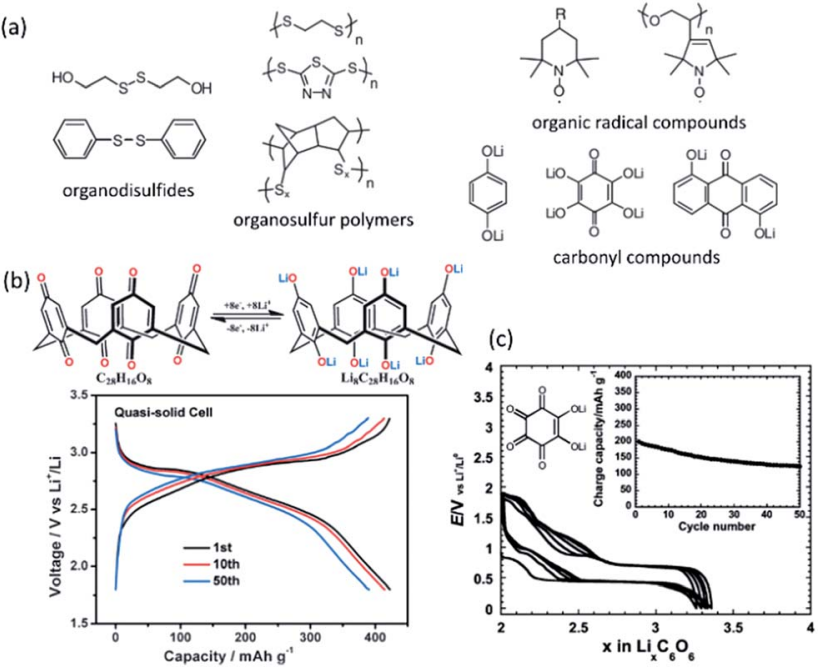

Fig. 14 (a) Selected samples of organic electrode materials for LIBS Reproduced with permission from ref. 183, copyright 2012, John Wiley and Sons. (b) A $8 \mathrm{Li}^{+} / 8 \mathrm{e}^{-}$reaction of a high capacity carbonyl compound calix[4]quinone $\left(\mathrm{C}_{28} \mathrm{H}_{16} \mathrm{O}_{8}\right)$ and its voltage profile at $\mathrm{C} / 5$. Reproduced with permission from ref. 184, copyright 2013, John Wiley and Sons. (c) Structure and voltage profile of a lithium salt of tetrahydroxybenzoquinone in a symmetric configuration cycled between $\mathrm{Li}_{2} \mathrm{C}_{6} \mathrm{O}_{6}$ and $\mathrm{Li}_{6} \mathrm{C}_{6} \mathrm{O}_{6}$ at a rate of $1 \mathrm{Li}^{+} / 10 \mathrm{~h}$. Reproduced with permission from ref. 185, copyright 2009, American Chemical Society.
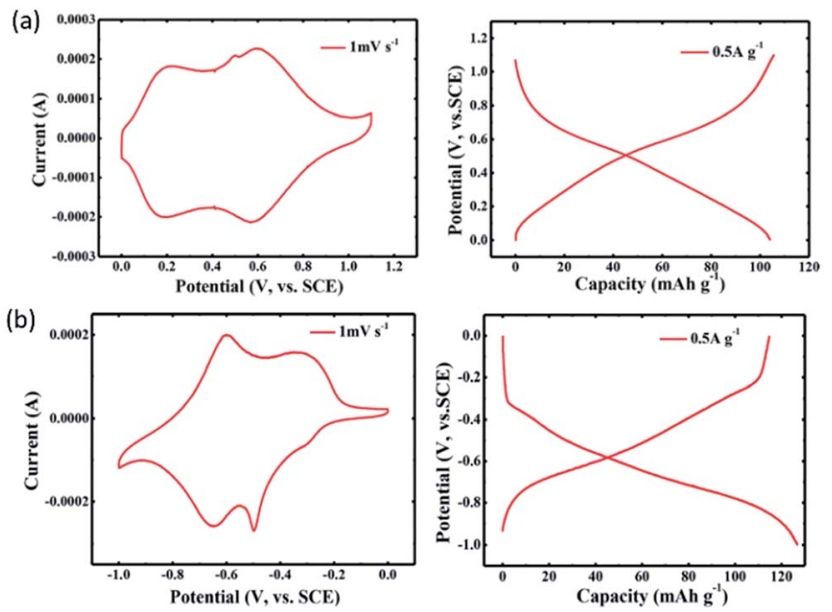

Fig. $15 \mathrm{CV}$ and charge/discharge curves $\left(0.5 \mathrm{~A} \mathrm{~g}^{-1}\right)$ for (a) polytriphenylamine cathode, (b) 1,4,5,8-naphthalenetetracarboxylic dianhydride-derived polyimide anode. Reproduced with permission from ref. 186, copyright 2017, John Wiley and Sons.

anode (Fig. 15b), without causing unwanted oxygen evolution (between 0.9 and $1.1 \mathrm{~V} v$ s. SCE) and hydrogen evolution reactions. A full cell test from 0.05 to $2.1 \mathrm{~V}$ showed a discharge capacity of $105 \mathrm{~mA} \mathrm{~h} \mathrm{~g}^{-1}$ at $0.5 \mathrm{~A} \mathrm{~g}^{-1}$, and $74 \mathrm{~mA} \mathrm{~h} \mathrm{~g}^{-1}$ at $10 \mathrm{~A}$ $\mathrm{g}^{-1}$, respectively. Over 700 cycles, the full cell exhibits stable cycling and a CE of about $100 \%$. The application of aqueous electrolyte for high voltage operation will be further discussed in the next section.

\subsection{Application of traditional electrode materials in aqueous electrolytes}

Conventionally, organic solvents are used for Li-ion batteries with broad electrochemical window and enable high-voltage electrodes. In contrast to the conventional organic carbonate electrolytes, recent efforts to develop high-voltage aqueous electrolytes open new opportunity for safe and low-cost operation. ${ }^{187,188}$ Concentrated aqueous electrolyte of LiTFSI enables an electrochemical window of about $3 \mathrm{~V}$, and an aqueous $\mathrm{LiMn}_{2} \mathrm{O}_{4} / \mathrm{Mo}_{6} \mathrm{~S}_{8}$ cell to be operated at about $2 \mathrm{~V}$ with stable cycling performance (capacity retention $68 \%$ with 1000 cycles at 4.5C, 78\% with 100 cycles at $0.15 \mathrm{C}$ ) (Fig. 16a). ${ }^{187}$ At highly concentrated electrolytes, the onset of oxygen evolution reaction was shifted to higher potential and the inner Helmholtz layer of the electrode is almost only covered by the $\mathrm{TFSI}^{-}$anions. ${ }^{189}$ The hydrogen and oxygen evolution reactions are largely inhibited. In addition, aqueous electrolytes have high ionic conductivity. The mass transport limitations of organic electrolytes can be alleviated. Accordingly, thicker electrode fabrication and fast charging/discharging are expected. Gordon et al. has demonstrated a salt concentration-dependent lithiation potential of $\mathrm{LiFePO}_{4}$ (Fig. 16b), and a good cyclability of $\mathrm{LiFePO}_{4}$ in saturated $\mathrm{LiNO}_{3}$ aqueous solutions over 500 cycles (Fig. 16c). ${ }^{190}$ Higher salt concentration leads to higher lithiation potential and improved cycling stability. It also alleviated electrolyte depletion at high current densities. ${ }^{191}$ 
(a)

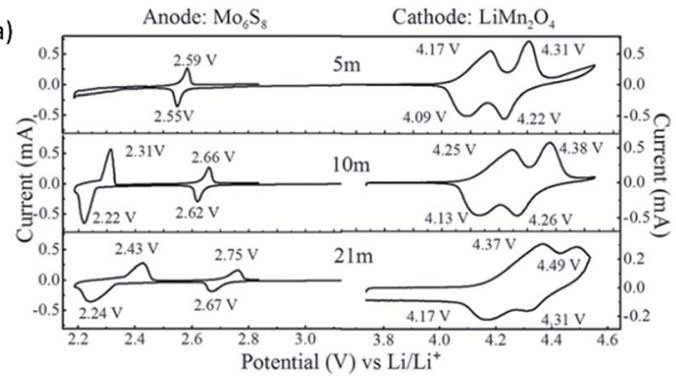

(b)

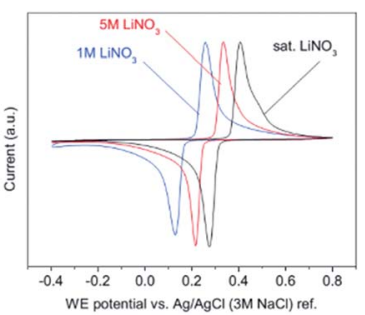

(c)

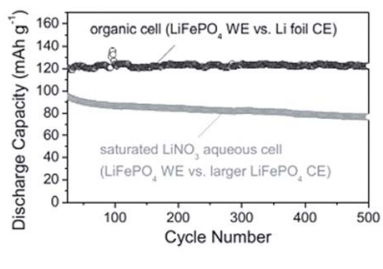

Fig. 16 (a) $\mathrm{CV}$ response $\left(0.1 \mathrm{mV} \mathrm{s}^{-1}\right)$ of active materials $\mathrm{LiMn}_{2} \mathrm{O}_{4}$ and $\mathrm{Mo}_{6} \mathrm{~S}_{8}$ in the concentrated $\mathrm{LiTFSI} / \mathrm{H}_{2} \mathrm{O}$ electrolytes with different molality $(m)$. Reproduced with permission from ref. 187, copyright 2015, The American Association for the Advancement of Science. (b) $\mathrm{CV}\left(0.3 \mathrm{mV} \mathrm{s}^{-1}\right)$ of $\mathrm{LiFePO}_{4}$ electrodes in aqueous $\mathrm{LiNO}_{3}$ solutions of varying molarity, and (c) discharge capacities (at $1.1 \mathrm{C}$ rate) of $\mathrm{LiFePO}_{4}$ in aqueous (partially delithiated $\mathrm{LiFePO}_{4}$ as counter electrode) and organic (1 M LiPF 6 in FEC/EMC, Li foil as counter electrode) electrolytes. Reproduced with permission from ref. 190, copyright 2015, John Wiley and Sons.

\subsection{Dual-ion batteries}

Graphite can act as a redox-amphoteric host for intercalating anions and cations, yielding acceptor-type and donor-type intercalated graphite, respectively. In contrast to conventional rocking-chair LIBs, wherein $\mathrm{Li}^{+}$ions are shuttled between the anode and cathode, the dual-ion batteries (also named as dualgraphite batteries, dual-carbon batteries) work through a simultaneous uptake of cations (for instance $\mathrm{Li}^{+}$) and anions (for instance $\mathrm{TFSI}^{-}$) from the electrolyte (for instance LiTFSI) into graphite anode and graphite cathode during charge, and a reversible release of both ions into the electrolyte during discharge (as schematically shown in Fig. 17a). ${ }^{192,193}$ In addition, dual-ion batteries are cost-effective and can be operated with higher voltage (for instance about $5 \mathrm{~V}$ ) without safety issues. Over cycling, a continuous change in the salt concentration in electrolyte occurs, leading to a variation of ionic conductivity. The success of such dual-ion batteries relies on the anion intercalation chemistry and formation of stable SEI. ${ }^{192}$ Numerous anion intercalation guests have been studied, including fluorinated anions $\left(\mathrm{BF}_{4}^{-}, \mathrm{PF}_{6}^{-}\right)$, oxo-complexes $\left(\mathrm{SO}_{4}{ }^{-}, \mathrm{NO}_{3}{ }^{-}, \mathrm{ClO}_{4}{ }^{-}\right)$, chlorocomplex anions $\left(\mathrm{GaCl}_{4}{ }^{-}, \mathrm{AlCl}_{4}{ }^{-}\right)$ and large anions such as bis(fluorosulfonyl)imide $\left(\mathrm{FSI}^{-}\right)$and TFSI $^{-}{ }^{194}$ The high intercalation potential of anions into graphite (typically beyond $4.4 \mathrm{~V} v s . \mathrm{Li}^{+} / \mathrm{Li}$, Fig. $17 \mathrm{~b}$ ) ${ }^{193}$ may cause oxidative decomposition of conventional carbonate solvents. The reversible capacity and CE depend largely on the character of anions (such as concentration, anion size, solvation with supporting solvents), the feature of carbon-based materials and the cycling voltage range. ${ }^{195,196}$

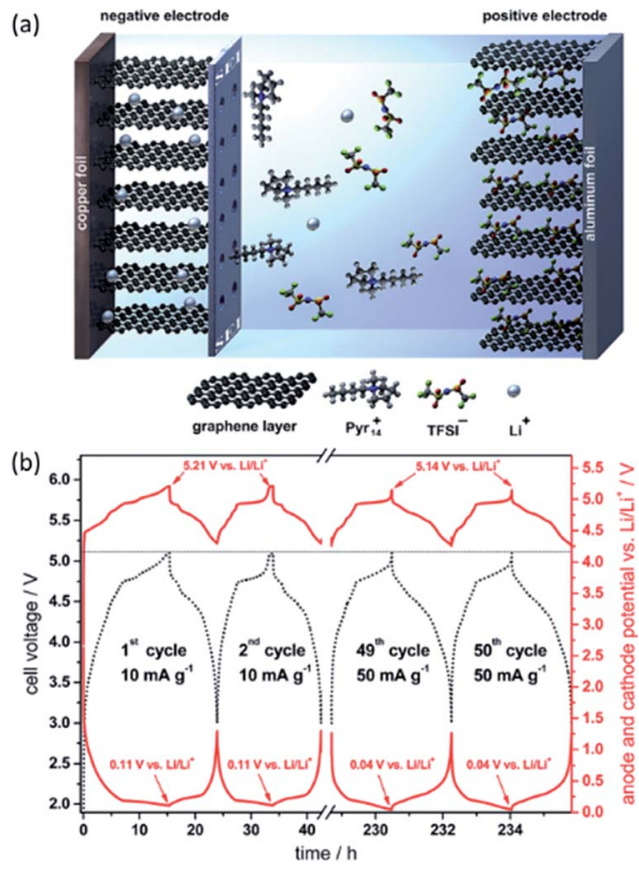

Fig. 17 (a) Schematic illustration of a dual-ion battery using graphite as both cathode and anode, with the formation of a stable SEl layer at the negative graphite electrode. (b) Cathode potential, anode potential (red curves) and cell voltage (dotted black curve) profiles. Reprinted with permission. ${ }^{193}$

Recently, organic intercalation materials to host anions have been demonstrated, ${ }^{197,198}$ which pave the way for developing new low cost Li-based organic rechargeable dual-ion batteries. Organic dilithium 2,5-(dianilino)terephthalate $\left(\mathrm{Li}_{2} \mathrm{DAnT}\right.$ ) shows reversible anion intercalation behavior (Fig. 18a). ${ }^{197}$ Different voltage plateau profiles have been observed, depending on the type and size $\left(\mathrm{ClO}_{4}{ }^{-}<\mathrm{PF}_{6}{ }^{-}<\mathrm{TFSI}^{-}\right)$of anions. The smallest $\mathrm{ClO}_{4}{ }^{-}$gives rise to the lowest voltage polarization, suggesting a lower level structural variation when accommodating smaller anion in the organic host. The electrochemical incorporation of $\mathrm{ClO}_{4}^{-}$anions has also been demonstrated using a poroushoneycomb organic framework (Fig. 18b and c). ${ }^{198}$ Fast ion transport and accordingly high rate capability can be achieved in such electrolyte-filled porous host structure. The capacity retention is about $60 \%$ by increasing the current density from $0.01 \mathrm{~A} \mathrm{~g}^{-1}\left(200 \mathrm{~mA} \mathrm{~h} \mathrm{~g}^{-1}\right)$ to $0.1 \mathrm{~A} \mathrm{~g}^{-1}\left(120 \mathrm{~mA} \mathrm{~h} \mathrm{~g}{ }^{-1}\right)$. At $1 \mathrm{Ag}^{-1}$, high capacity retention of about $80 \%$ was observed over 7000 cycles.

\subsection{Symmetric electrodes}

Besides graphite, many other materials can also be used as both cathode and anode in a symmetric battery system, ${ }^{199}$ relying on the fact that an identical electrode material can work at different potential ranges (Fig. 19a). ${ }^{200-202}$ Fig. 19b shows that for $\mathrm{LiVPO}_{4} \mathrm{~F}, \mathrm{~V}^{4+} / \mathrm{V}^{3+}$ and $\mathrm{V}^{3+} / \mathrm{V}^{2+}$ redox reactions can occur at about 4.3 and $1.8 \mathrm{~V}$, respectively, allowing a cell voltage of $2.4 \mathrm{~V}$ in a symmetric LIB. $^{202}$ Li-based batteries with symmetric electrodes have merits of reduced manufacture cost, simple 
(a)
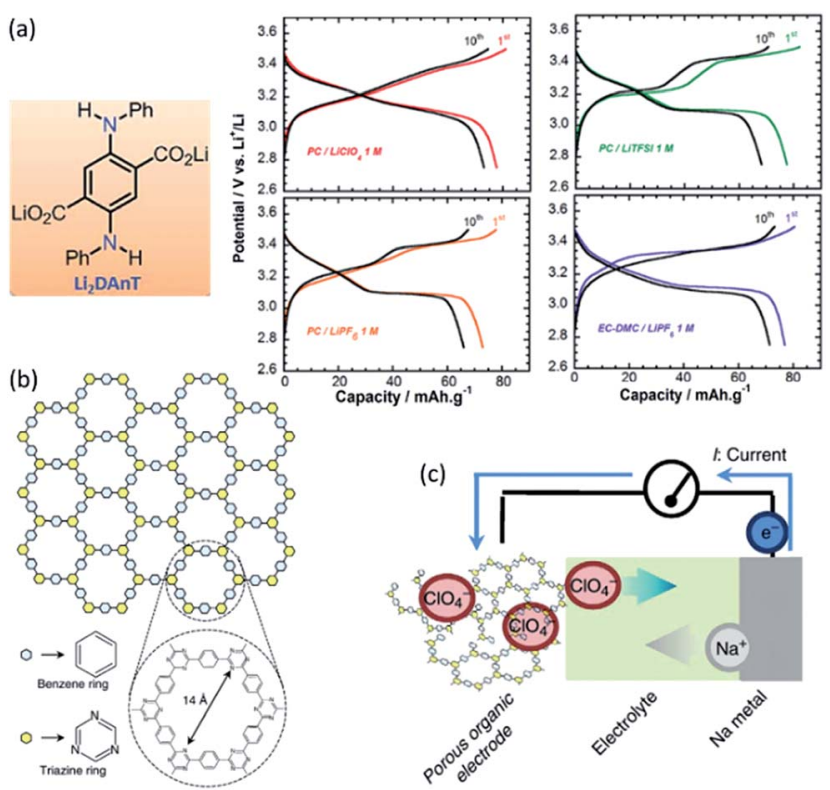

Fig. 18 (a) Structure of $\mathrm{Li}_{2} \mathrm{DAnT}$ and voltage profiles of $\mathrm{Li}_{2} \mathrm{DAnT}$ when hosting different anions. ${ }^{197}$ (b) Porous organic anion host of having a honeycomb structure with a pore diameter of $1.4 \mathrm{~nm}$, and (c) discharging process with $\mathrm{ClO}_{4}{ }^{-}$anions move out from the organic host. Reproduced with permission from ref. 198, copyright 2013, Nature Publishing Group.

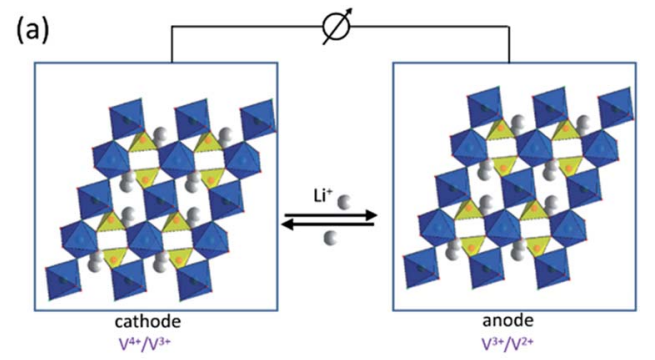

(b)

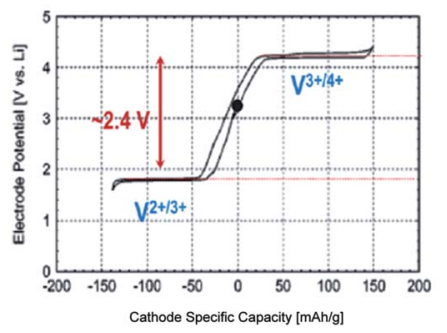

Fig. 19 (a) Schematic illustration of a symmetric LIB with two redox couples of $\mathrm{V}^{4+} / \mathrm{V}^{3+}$ and $\mathrm{V}^{3+} / \mathrm{V}^{2+}$ in the $\mathrm{LiVPO}_{4} \mathrm{~F}$. Reproduced with permission from ref. 201, copyright 2011, American Chemical Society. (b) (De)lithiation reactions for a $\mathrm{Li} / \mathrm{LiVPO}_{4} \mathrm{~F}$ cell from 1.6 to $4.4 \mathrm{~V}$ showing two potential steps with a gap of about $2.4 \mathrm{~V}$. Reproduced with permission from ref. 202, copyright 2013, American Chemical Society.

process, improved safety and ability of charging in both directions. Such batteries are expected to be able to tolerate large volume variation during (de)lithiation. Volume expansion from one side of the cell can be buffered from the volume shrinkage in the other side. Table 2 summarizes several electrode materials that can be used in symmetric rechargeable batteries. ${ }^{202-208}$
Symmetric cells are well-suited for studying the cycling reactions between electrode materials and electrolyte, ${ }^{209}$ and the degradation mechanism. ${ }^{210}$ Symmetric electrodes have also been assembled and demonstrated in supercapacitors, ${ }^{211}$ fuel cells, ${ }^{212}$ and in redox flow batteries with the attempt to avoid cross-contamination of active species. ${ }^{213-216}$

\subsection{Semi-solid Li-flow batteries}

Although significant advances in electrochemical energy storage devices, development of low-cost and high energy density system remains a challenge, especially for medium- and large-scale applications. Nowadays, many flow-assisted electrochemical systems based on different active materials are considered as an alternative route toward scalable and versatile energy storage. For such system, active electrolytes (soluble solutions or solid suspensions) are stored in two external individual tanks and circulated through the electrochemical cell to achieve a full redox reaction. ${ }^{217}$ For the conventional redox flow batteries, the solubility of active species in both the catholyte and anolyte is normally less than $2 \mathrm{M}$, which limits the volumetric energy density (typically below $30 \mathrm{~W} \mathrm{~h} \mathrm{~L}^{-1}$ ). ${ }^{218}$

In 2011, a new concept of semi-solid lithium flow battery was first introduced by Chiang et al. ${ }^{219}$ as a way to utilize flowable intercalation materials as active suspension for enhanced energy storage (Fig. 20a). A high energy density of $397 \mathrm{~W} \mathrm{~h} \mathrm{~L}^{-1}$ has been achieved for a semi-solid $\mathrm{LiCoO}_{2} / \mathrm{Li}_{4} \mathrm{Ti}_{5} \mathrm{O}_{12}$ battery. Such system combines the advantages of both lithium-ion batteries with high energy-dense materials, and redox flow batteries with large design flexibility. The electron transfer between the active suspension materials and the current collector occurs through the formation of a percolation network among the agglomerated active solid materials and conductive carbon additives. A high volumetric capacity of $550 \mathrm{~A} \mathrm{~h}$ $\mathrm{L}_{\text {catholyte }}{ }^{-1}$ (corresponding to $580 \mathrm{~W} \mathrm{~h} \mathrm{~L}_{\text {catholyte }+\mathrm{Li}}{ }^{-1}$ ) has been achieved with high CE $(>95 \%)$ for a redox flow battery with multiple redox couples of $\mathrm{I}_{3}{ }^{-} / \mathrm{I}^{-}$and $\mathrm{S} / \mathrm{S}^{2-} .220$

For semi-solid Li-flow batteries, carbon additives are needed for facilitating the electron transfer between the current collector and active solid particles (typically with low electrical conductivity). High content of carbon is necessary to form a percolating conductive network, which however leads to increased viscosity of the suspension and high pressure drop through the flow field. Reaction rate drops due to reduced bulk diffusion. The full utilization of active materials in this case cannot be realized. A redox targeting concept has been developed by Wang et al. ${ }^{221,222}$ to achieve carbon-free operation with statically stored active solid particles (Fig. 20b). A redox shuttle molecule is added into the electrolyte to have electron transfer reaction on the current collector inside the cell, while having chemical (de)lithiation reaction of active solid materials in the external tank (Fig. 20c). High solid content up to about $10 \mathrm{M}$ can be used, whereas a diluted concentration of shuttle molecule of only several $\mathrm{mM}$ is sufficient in such system.

The concept of redox flow lithium batteries has been further expanded to the applications of redox flow $\mathrm{Li}_{-} \mathrm{O}_{2}$ batteries, ${ }^{223,224}$ redox flow Li-S batteries. ${ }^{225-228}$ For the traditional Li-S batteries, 
Table 2 Summary of selected electrode materials for symmetric batteries

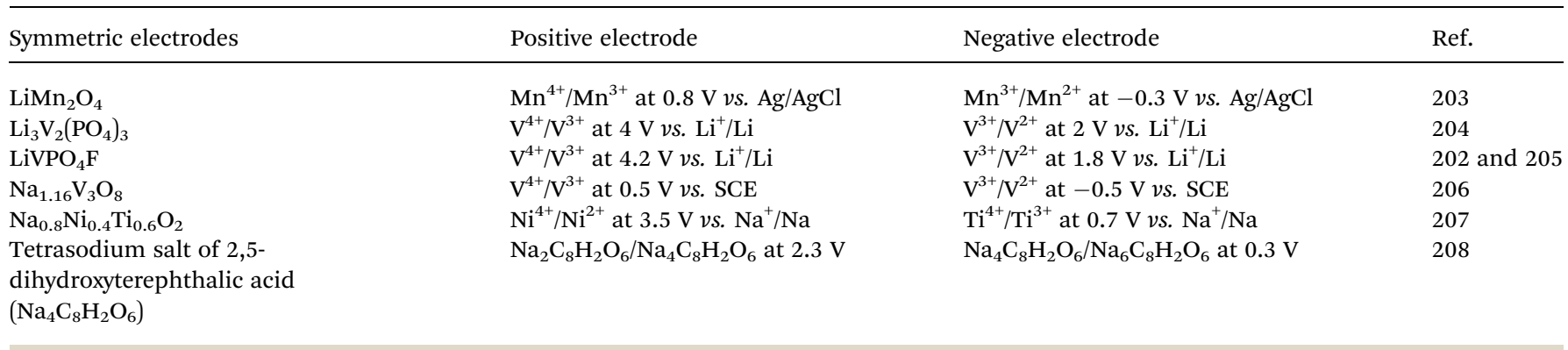

(a)

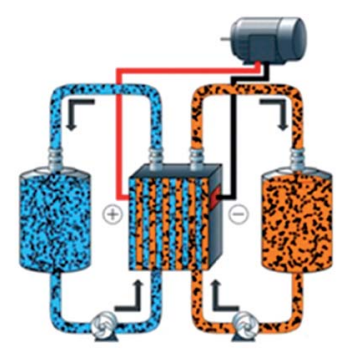

(b)

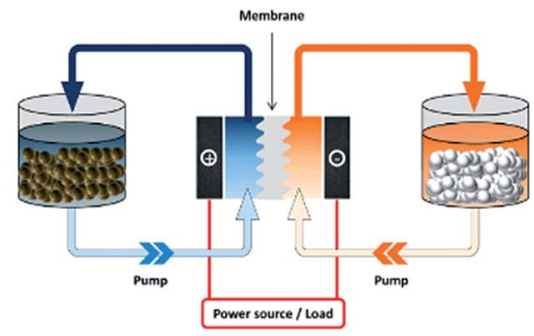

(c)

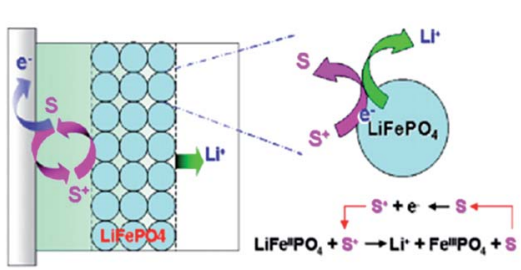

Fig. 20 (a) Schematics of a semi-solid redox flow battery. Reproduced with permission from ref. 219, copyright 2011, John Wiley and Sons. (b) Illustration of a redox flow battery with statically stored solid active compounds in the tanks, and redox shuttle molecules circulating through the cell. ${ }^{221}$ (c) Working principle of reactions between the statically stored solid $\mathrm{LiFePO}_{4}$ with the flowing redox shuttle molecule $\left(\mathrm{S}^{+} / \mathrm{S}\right){ }^{221}$ Reproduced with permission.

the formation of soluble polysulfide species leads to detrimental self-discharge. However, such attributes can be utilized in flow battery systems. The successful development of such new systems relies on the progress of selection and modification of carbon-based electrode materials, ${ }^{229}$ electrocatalysts, ${ }^{230}$ electrolytes $^{231,232}$ and membranes. ${ }^{233,234}$

\section{Conclusions and perspective}

Electrodes with the issues of low electron/ion conductivities, large structure variation, and poor interfacial stability with electrolytes during the charge-discharge process limit the practical application of LIBs. The significant development of nanomaterials employed in both cathode and anode of LIBs to boost the performance has been discussed. By rationally controlling the nanoarchitectures of Si-based anode materials and using novel carbon-based anode materials, steady and high capacity over long-term cycling has been demonstrated. Nanoscale cathode materials with stable frameworks and fast $\mathrm{Li}^{+}$ conductivities can be applied as protective surface layer to promote the cycling performance of other high-capacity cathode materials. With a concentration gradient of transition metals from the outer surface to inner bulk, high energy density lithium metal oxide-based cathode materials can reach a compromise between good thermal and interface stabilities, high capacity and high rate. To tackle with the sluggish kinetics and shuttle effects encountered in Li-S batteries, chemical binding and physical confinement are effective strategies to assure electric contact and to inhibit dissolution loss of active species, respectively. Accordingly, durable and high capacity cathode materials can be achieved.

Parallel to the studies of electrodes themselves, intensive efforts have been also taken by applying a nanoscale coating through various strategies. Surface modifications of the electrode materials make it possible to tolerate volume change and suppress side reactions. Further extensive investigations in surface modifications are required: (1) a rational design of strong chemical bonding between bulk and coating; (2) a multifunctional coating (e.g. fabricated by layer/layer and hollow shell) is desirable to simultaneously meet requirements, including large capacity, good rate capability and cycling stability; (3) detailed fundamental investigations of surface coating mechanisms are still needed.

Efforts to develop new low-cost active electrode materials using multi-electron transfer organic compounds, safe systems with high-voltage aqueous electrolytes, versatile battery design including dual-ion configuration, symmetric electrodes, semisolid electrodes and flexible operation with flow electrolytes may open new avenue for advanced energy storage technologies in the future.

\section{Acknowledgements}

H. Z. gratefully acknowledges the financial support from the National Natural Science Foundation of China (no. 21603272). C. M. and J. L. acknowledge the funding support from the U.S. 
Department of Energy (DOE) under contract DE-AC0500OR22725, and the Office of Energy Efficiency and Renewable Energy (EERE) Vehicle Technologies Office (VTO) (Deputy Director: David Howell) Applied Battery Research subprogram (Program Manager: Peter Faguy). R. C. thanks the basic research funding from KIST Europe.

\section{References}

1 M. S. Whittingham, Chem. Rev., 2004, 104, 4271-4301.

2 K. Mitzushima, P. C. Jones, P. J. Wiseman and J. Goodenough, Mater. Res. Bull., 1980, 15, 783-789.

3 A. K. Padhi, K. S. Nanjundaswamy and J. B. Goodenough, J. Electrochem. Soc., 1997, 144, 1188-1194.

4 G. E. Blomgren, J. Electrochem. Soc., 2017, 164, A5019A5025.

5 J. B. Goodenough and K.-S. Park, J. Am. Chem. Soc., 2013, 135, 1167-1176.

6 R. Van Noorden, Nature, 2014, 507, 26-28.

7 D. Andre, S.-J. Kim, P. Lamp, S. F. Lux, F. Maglia, O. Paschos and B. Stiaszny, J. Mater. Chem. A, 2015, 3, 6709-6732.

8 Y. Lyu, N. Zhao, E. Hu, R. Xiao, X. Yu, L. Gu, X.-Q. Yang and H. Li, Chem. Mater., 2015, 27, 5238-5252.

9 D. Mohanty, J. Li, D. P. Abraham, A. Huq, E. A. Payzant, D. L. Wood and C. Daniel, Chem. Mater., 2014, 26, 62726280.

10 M. S. Islam, R. Dominko, C. Masquelier, C. Sirisopanaporn, A. R. Armstrong and P. G. Bruce, J. Mater. Chem., 2011, 21, 9811-9818.

11 R. Chen, S. Ren, M. Knapp, D. Wang, R. Witter, M. Fichtner and H. Hahn, Adv. Energy Mater., 2015, 5, 1401814.

12 R. Chen, E. Maawad, M. Knapp, S. Ren, P. Beran, R. Witter and R. Hempelmann, RSC Adv., 2016, 6, 65112-65118.

13 M. N. Obrovac and V. L. Chevrier, Chem. Rev., 2014, 114, 11444-11502.

14 R. Chen, R. Heinzmann, S. Mangold, V. S. K. Chakravadhanula, H. Hahn and S. Indris, J. Phys. Chem. C, 2013, 117, 884-893.

15 G. Hernández, N. Casado, R. Coste, D. Shanmukaraj, L. Rubatat, M. Armand and D. Mecerreyes, RSC Adv., 2015, 5, 17096-17103.

16 J. W. Choi and D. Aurbach, Nat. Rev. Mater., 2016, 1, 16013. 17 N. Yabuuchi, Chem. Lett., 2017, 46, 412-422.

18 J. Lu, Z. Chen, Z. Ma, F. Pan, L. A. Curtiss and K. Amine, Nat. Nanotechnol., 2016, 11, 1031-1038.

19 M. Okubo, Y. Mizuno, H. Yamada, J. Kim, E. Hosono, H. Zhou, T. Kudo and I. Honma, ACS Nano, 2010, 4, 741752.

20 C. Lai, Y. Y. Dou, X. Li and X. P. Gao, J. Power Sources, 2010, 195, 3676-3679.

21 V. Augustyn, J. Come, M. A. Lowe, J. W. Kim, P.-L. Taberna, S. H. Tolbert, H. D. Abruña, P. Simon and B. Dunn, Nat. Mater., 2013, 12, 518-522.

22 L. Croguennec and M. R. Palacin, J. Am. Chem. Soc., 2015, 137, 3140-3156.

23 J. Li, B. L. Armstrong, J. Kiggans, C. Daniel and D. L. Wood, J. Electrochem. Soc., 2013, 160, A201-A206.
24 P. G. Bruce, B. Scrosati and J. M. Tarascon, Angew. Chem., Int. Ed., 2008, 47, 2930-2946.

25 J. Li, C. Daniel and D. Wood, J. Power Sources, 2011, 196, 2452-2460.

26 G. Hautier, A. Jain, T. Mueller, C. Moore, S. P. Ong and G. Ceder, Chem. Mater., 2013, 25, 2064-2074.

27 S. Goriparti, E. Miele, F. De Angelis, E. Di Fabrizio, R. Proietti Zaccaria and C. Capiglia, J. Power Sources, 2014, 257, 421-443.

28 T. Chen, Q. Zhang, J. Xu, J. Pan and Y.-T. Cheng, RSC Adv., 2016, 6, 29308-29313.

29 S. J. An, J. Li, C. Daniel, H. M. Meyer III, S. E. Trask, B. J. Polzin and D. L. Wood III, ACS Appl. Mater. Interfaces, 2017, 9, 18799-18808.

$30 \mathrm{H}$. Li, X. Huang, L. Chen, Z. Wu and Y. Liang, Electrochem. Solid-State Lett., 1999, 2, 547-549.

31 H. Kim, M. Seo, M. H. Park and J. Cho, Angew. Chem., Int. Ed., 2010, 49, 2146-2149.

32 J. P. Maranchi, A. F. Hepp, A. G. Evans, N. T. Nuhfer and P. N. Kumta, J. Electrochem. Soc., 2006, 153, A1246.

33 L.-F. Cui, L. Hu, J. W. Choi and Y. Cui, ACS Nano, 2010, 4, 3671-3678.

34 C. K. Chan, H. Peng, G. Liu, K. McIlwrath, X. F. Zhang, R. A. Huggins and Y. Cui, Nat. Nanotechnol., 2008, 3, 31-35.

35 T. Song, J. Xia, J. H. Lee, D. H. Lee, M. S. Kwon, J. M. Choi, J. Wu, S. K. Doo, H. Chang, W. I. Park, D. S. Zang, H. Kim, Y. Huang, K. C. Hwang, J. A. Rogers and U. Paik, Nano Lett., 2010, 10, 1710-1716.

36 K. McCormac, I. Byrd, R. Brannen, B. Seymour, J. Li and J. Wu, Phys. Status Solidi A, 2015, 212, 877-881.

37 C. K. Chan, R. N. Patel, M. J. O'Connell, B. A. Korgel and Y. Cui, ACS Nano, 2010, 4, 1443-1450.

38 M.-H. Park, M. G. Kim, J. Joo, K. Kim, J. Kim, S. Ahn, Y. Cui and J. Cho, Nano Lett., 2009, 9, 3844-3847.

39 H. Wu, G. Chan, J. W. Choi, I. Ryu, Y. Yao, M. T. McDowell, S. W. Lee, A. Jackson, Y. Yang, L. Hu and Y. Cui, Nat. Nanotechnol., 2012, 7, 310-315.

40 A. Magasinski, P. Dixon, B. Hertzberg, A. Kvit, J. Ayala and G. Yushin, Nat. Mater., 2010, 9, 353-358.

41 Y. Yao, M. T. McDowell, I. Ryu, H. Wu, N. Liu, L. Hu, W. D. Nix and Y. Cui, Nano Lett., 2011, 11, 2949-2954.

42 H. Ma, F. Cheng, J. Y. Chen, J. Z. Zhao, C. S. Li, Z. L. Tao and J. Liang, Adv. Mater., 2007, 19, 4067-4070.

43 H. Kim, B. Han, J. Choo and J. Cho, Angew. Chem., Int. Ed., 2008, 47, 10151-10154.

44 D. Chen, X. Mei, G. Ji, M. Lu, J. Xie, J. Lu and J. Y. Lee, Angew. Chem., Int. Ed., 2012, 51, 2409-2413.

45 X. Li, C. Yan, J. Wang, A. Graff, S. L. Schweizer, A. Sprafke, O. G. Schmidt and R. B. Wehrspohn, Adv. Energy Mater., 2015, 5, 1401556.

46 S. Li, J. Niu, Y. C. Zhao, K. P. So, C. Wang, C. A. Wang and J. Li, Nat. Commun., 2015, 6, 7872.

47 H. Zhang, X. Zhong, J. C. Shaw, L. Liu, Y. Huang and X. Duan, Energy Environ. Sci., 2013, 6, 2621-2625.

48 U. Kasavajjula, C. Wang and A. J. Appleby, J. Power Sources, 2007, 163, 1003-1039. 
49 H.-T. Kwon, C. K. Lee, K.-J. Jeon and C.-M. Park, ACS Nano, 2016, 10, 5701-5709.

50 Y. Liu, R. Ma, Y. He, M. Gao and H. Pan, Adv. Funct. Mater., 2014, 24, 3944-3952.

51 G. Chen, L. Yan, H. Luo and S. Guo, Adv. Mater., 2016, 28, 7580-7602.

52 J. Yang, X.-Y. Zhou, J. Li, Y.-L. Zou and J.-J. Tang, Mater. Chem. Phys., 2012, 135, 445-450.

53 J. Sun, H. Liu, X. Chen, D. G. Evans, W. Yang and X. Duan, Adv. Mater., 2013, 25, 1125-1130.

54 Z. L. Yu, S. Xin, Y. You, L. Yu, Y. Lin, D. W. Xu, C. Qiao, Z. H. Huang, N. Yang, S. H. Yu and J. B. Goodenough, J. Am. Chem. Soc., 2016, 138, 14915-14922.

55 S. Iijima, Nature, 1991, 354, 56-58.

56 V. Meunier, J. Kephart, C. Roland and J. Bernholc, Phys. Rev. Lett., 2002, 88, 075506.

57 C. M. Schauerman, M. J. Ganter, G. Gaustad, C. W. Babbitt, R. P. Raffaelle and B. J. Landi, J. Mater. Chem., 2012, 22, 12008.

58 H. S. Oktaviano, K. Yamada and K. Waki, J. Mater. Chem., 2012, 22, 25167.

59 H. Yoo, A. P. Tiwari, J. Lee, D. Kim, J. H. Park and H. Lee, Nanoscale, 2015, 7, 3404-3409.

60 W.-J. Yu, L. Zhang, P.-X. Hou, F. Li, C. Liu and H.-M. Cheng, Adv. Energy Mater., 2016, 6, 1501755.

61 J.-Y. Hwang, H. M. Kim, S.-K. Lee, J.-H. Lee, A. Abouimrane, M. A. Khaleel, I. Belharouak, A. Manthiram and Y.-K. Sun, Adv. Energy Mater., 2016, 6, 1501480.

62 G. Huang, F. Zhang, X. Du, Y. Qin, D. Yin and L. Wang, ACS Nano, 2015, 9, 1592-1599.

63 R. A. Susantyoko, X. Wang, Q. Xiao, E. Fitzgerald and Q. Zhang, Carbon, 2014, 68, 619-627.

64 D. Pan, S. Wang, B. Zhao, M. Wu, H. Zhang, Y. Wang and Z. Jiao, Chem. Mater., 2009, 21, 3136-3142.

65 K. Chang and W. Chen, ACS Nano, 2011, 5, 4720-4728.

66 L. Jiang, B. Lin, X. Li, X. Song, H. Xia, L. Li and H. Zeng, ACS Appl. Mater. Interfaces, 2016, 8, 2680-2687.

67 M. Srivastava, J. Singh, T. Kuila, R. K. Layek, N. H. Kim and J. H. Lee, Nanoscale, 2015, 7, 4820-4868.

68 J. Wu, I. Byrd, C. Jin, J. Li, H. Chen, T. Camp, R. Bujol, A. Sharma and H. Zhang, ChemElectroChem, 2017, 4, 1181-1189.

69 B. Kang and G. Ceder, Nature, 2009, 458, 190-193.

70 R. Malik, F. Zhou and G. Ceder, Nat. Mater., 2011, 10, 587590.

71 H. Liu, F. C. Strobridge, O. J. Borkiewicz, K. M. Wiaderek, K. W. Chapman, P. J. Chupas and C. P. Grey, Science, 2014, 344, 1252817.

72 J. Lim, Y. Li, D. H. Alsem, H. So, S. C. Lee, P. Bai, D. A. Cogswell, X. Liu, N. Jin, Y.-s. Yu, N. J. Salmon, D. A. Shapiro, M. Z. Bazant, T. Tyliszczak and W. C. Chueh, Science, 2016, 353, 566.

73 F. Boucher, J. Gaubicher, M. Cuisinier, D. Guyomard and P. Moreau, J. Am. Chem. Soc., 2014, 136, 9144-9157.

74 Z. Wu, S. Ji, T. Liu, Y. Duan, S. Xiao, Y. Lin, K. Xu and F. Pan, Nano Lett., 2016, 16, 6357-6363.
75 Y. K. Sun, Z. Chen, H. J. Noh, D. J. Lee, H. G. Jung, Y. Ren, S. Wang, C. S. Yoon, S. T. Myung and K. Amine, Nat. Mater., 2012, 11, 942-947.

76 J. H. Lee, C. S. Yoon, J.-Y. Hwang, S.-J. Kim, F. Maglia, P. Lamp, S.-T. Myung and Y.-K. Sun, Energy Environ. Sci., 2016, 9, 2152-2158.

77 F. Jiao, K. M. Shaju and P. G. Bruce, Angew. Chem., Int. Ed., 2005, 44, 6550-6553.

78 Y. Zhou and H. Li, J. Mater. Chem., 2002, 12, 681-686.

79 P. G. Bruce, S. A. Freunberger, L. J. Hardwick and J. M. Tarascon, Nat. Mater., 2011, 11, 19-29.

80 X. Liu, J.-Q. Huang, Q. Zhang and L. Mai, Adv. Mater., 2017, 29, 1601759.

81 M. Wild, L. O'Neill, T. Zhang, R. Purkayastha, G. Minton, M. Marinescu and G. J. Offer, Energy Environ. Sci., 2015, 8, 3477-3494.

82 G. L. Xu, Y. F. Xu, J. C. Fang, X. X. Peng, F. Fu, L. Huang, J. T. Li and S. G. Sun, ACS Appl. Mater. Interfaces, 2013, 5, 10782-10793.

83 G. Li, J. Sun, W. Hou, S. Jiang, Y. Huang and J. Geng, Nat. Commun., 2016, 7, 10601.

84 M. Q. Zhao, H. J. Peng, G. L. Tian, Q. Zhang, J. Q. Huang, X. B. Cheng, C. Tang and F. Wei, Adv. Mater., 2014, 26, 7051-7058.

85 J. S. Lee, W. Kim, J. Jang and A. Manthiram, Adv. Energy Mater., 2017, 5, 1601943.

86 G. Zheng, Q. Zhang, J. J. Cha, Y. Yang, W. Li, Z. W. She and Y. Cui, Nano Lett., 2013, 13, 1265-1270.

87 J. Song, M. L. Gordin, T. Xu, S. Chen, Z. Yu, H. Sohn, J. Lu, Y. Ren, Y. Duan and D. Wang, Angew. Chem., Int. Ed., 2015, 54, 4325-4329.

88 L. Fei, X. Li, W. Bi, Z. Zhuo, W. Wei, L. Sun, W. Lu, X. Wu, K. Xie, C. Wu, H. L. Chan and Y. Wang, Adv. Mater., 2015, 27, 5936-5942.

89 X. Ji, S. Evers, R. Black and L. F. Nazar, Nat. Commun., 2011, 2, 325 .

90 W. Miao, C. Zhang, Y. Cai, Y. Zhang and H. Lu, Analyst, 2016, 141, 2435-2440.

91 X. Liang and L. F. Nazar, ACS Nano, 2016, 10, 4192-4198.

92 Z. Li, J. Zhang and X. W. Lou, Angew. Chem., Int. Ed., 2015, 54, 12886-12890.

93 S. Evers, T. Yim and L. F. Nazar, J. Phys. Chem. C, 2012, 116, 19653-19658.

94 Z. Wei Seh, W. Li, J. J. Cha, G. Zheng, Y. Yang, M. T. McDowell, P. C. Hsu and Y. Cui, Nat. Commun., 2013, 4, 1331.

95 C. Mao, F. Zuo, Y. Hou, X. Bu and P. Feng, Angew. Chem., Int. Ed., 2014, 53, 10485-10489.

96 Z. Liang, G. Zheng, W. Li, Z. W. Seh, H. Yao, K. Yan, D. Kong and Y. Cui, ACS Nano, 2014, 8, 5249-5256.

97 X. Tao, J. Wang, Z. Ying, Q. Cai, G. Zheng, Y. Gan, H. Huang, Y. Xia, C. Liang, W. Zhang and Y. Cui, Nano Lett., 2014, 14, 5288-5294.

98 Q. Pang, D. Kundu, M. Cuisinier and L. F. Nazar, Nat. Commun., 2014, 5, 4759.

99 Z. W. Seh, J. H. Yu, W. Li, P. C. Hsu, H. Wang, Y. Sun, H. Yao, Q. Zhang and Y. Cui, Nat. Commun., 2014, 5, 5017. 
100 L. Ma, S. Wei, H. L. Zhuang, K. E. Hendrickson, R. G. Hennig and L. A. Archer, J. Mater. Chem. A, 2015, 3, 19857-19866.

101 Q. Pang, D. Kundu and L. F. Nazar, Mater. Horiz., 2016, 3, 130-136.

102 Z. Yuan, H. J. Peng, T. Z. Hou, J. Q. Huang, C. M. Chen, D. W. Wang, X. B. Cheng, F. Wei and Q. Zhang, Nano Lett., 2016, 16, 519-527.

103 L. Xu, Y. Hu, H. Zhang, H. Jiang and C. Li, ACS Sustainable Chem. Eng., 2016, 4, 4251-4255.

104 Y. Feng, Y. Zhang, Y. Wei, X. Song, Y. Fu and V. S. Battaglia, Phys. Chem. Chem. Phys., 2016, 18, 30630-30642.

105 T. Lei, W. Chen, J. Huang, C. Yan, H. Sun, C. Wang, W. Zhang, Y. Li and J. Xiong, Adv. Energy Mater., 2017, 7, 1601843.

106 K. X. Wang, X. H. Li and J. S. Chen, Adv. Mater., 2015, 27, 527-545.

107 X. Meng, X. Q. Yang and X. Sun, Adv. Mater., 2012, 24, 35893615.

108 Q. Wang, D.-A. Zhang, Q. Wang, J. Sun, L.-L. Xing and X.-Y. Xue, Electrochim. Acta, 2014, 146, 411-418.

109 C. Guan, X. Wang, Q. Zhang, Z. Fan, H. Zhang and H. J. Fan, Nano Lett., 2014, 14, 4852-4858.

110 J.-S. Kim, D. W. Kim, H. T. Jung and J. W. Choi, Chem. Mater., 2015, 27, 2780-2787.

111 I. V. Ferrari, M. Braglia, T. Djenizian, P. Knauth and M. L. Di Vona, J. Power Sources, 2017, 353, 95-103.

112 N. Kamaya, K. Homma, Y. Yamakawa, M. Hirayama, R. Kanno, M. Yonemura, T. Kamiyama, Y. Kato, S. Hama, K. Kawamoto and A. Mitsui, Nat. Mater., 2011, 10, 682-686.

113 K. Yan, H.-W. Lee, T. Gao, G. Zheng, H. Yao, H. Wang, Z. Lu, Y. Zhou, Z. Liang, Z. Liu, S. Chu and Y. Cui, Nano Lett., 2014, 14, 6016-6022.

114 W. Liu, D. Lin, A. Pei and Y. Cui, J. Am. Chem. Soc., 2016, 138, 15443-15450.

115 W. Liu, W. Li, D. Zhuo, G. Zheng, Z. Lu, K. Liu and Y. Cui, ACS Cent. Sci., 2017, 3, 135-140.

116 H. Zhang, M. Yao and X. Liu, Composite anode of lithium-ion batteries, West Virginia University, Morgantown, WV, United States, 2014.

117 A. Magasinski, P. Dixon, B. Hertzberg, A. Kvit, J. Ayala and G. Yushin, Nat. Mater., 2010, 9, 353-358.

118 B. Fuchsbichler, C. Stangl, H. Kren, F. Uhlig and S. Koller, J. Power Sources, 2011, 196, 2889-2892.

119 J. Li, X. Xiao, Y.-T. Cheng and M. W. Verbrugge, J. Phys. Chem. Lett., 2013, 4, 3387-3391.

120 B. Zhu, N. Liu, M. McDowell, Y. Jin, Y. Cui and J. Zhu, Nano Energy, 2015, 13, 620-625.

121 W. Li, Y. Tang, W. Kang, Z. Zhang, X. Yang, Y. Zhu, W. Zhang and C.-S. Lee, Small, 2015, 11, 1345-1351.

122 X. Xiao, P. Lu and D. Ahn, Adv. Mater., 2011, 23, 3911-3915.

123 G. Liu, S. Xun, N. Vukmirovic, X. Song, P. Olalde-Velasco, H. Zheng, V. S. Battaglia, L. Wang and W. Yang, Adv. Mater., 2011, 23, 4679-4683.

124 J. Chang, X. Huang, G. Zhou, S. Cui, P. B. Hallac, J. Jiang, P. T. Hurley and J. Chen, Adv. Mater., 2014, 26, 758-764.
125 A. Kohandehghan, P. Kalisvaart, K. Cui, M. Kupsta, E. Memarzadeh and D. Mitlin, J. Mater. Chem. A, 2013, 1, 12850-12861.

126 E. L. Memarzadeh, W. P. Kalisvaart, A. Kohandehghan, B. Zahiri, C. M. B. Holt and D. Mitlin, J. Mater. Chem., 2012, 22, 6655-6668.

127 M. T. McDowell, S. Woo Lee, C. Wang and Y. Cui, Nano Energy, 2012, 1, 401-410.

128 G. Jeong, J. G. Kim, M. S. Park, M. Seo, S. M. Hwang, Y. U. Kim, Y. J. Kim, J. H. Kim and S. X. Dou, ACS Nano, 2014, 8, 2977-2985.

129 W. Luo, Y. Wang, L. Wang, W. Jiang, S.-L. Chou, S. X. Dou, H. K. Liu and J. Yang, ACS Nano, 2016, 10, 10524-10532.

130 J. Liu, Y. Wen, P. A. van Aken, J. Maier and Y. Yu, Nano Lett., 2014, 14, 6387-6392.

131 Y. Xu, H. Wang, R. Zhu, C. Liu, X. Wu and B. Zhang, Chem.Asian J., 2013, 8, 1120-1127.

132 J. Liu, X. Xu, R. Hu, L. Yang and M. Zhu, Adv. Energy Mater., 2016, 6, 1600256.

133 C. Wang, L. Yin, D. Xiang and Y. Qi, ACS Appl. Mater. Interfaces, 2012, 4, 1636-1642.

134 C. Zhu, X. Xia, J. Liu, Z. Fan, D. Chao, H. Zhang and H. J. Fan, Nano Energy, 2014, 4, 105-112.

135 X. Hou, X. Wang, B. Liu, Q. Wang, Z. Wang, D. Chen and G. Shen, ChemElectroChem, 2014, 1, 108-115.

136 J.-H. Jeun, K.-Y. Park, D.-H. Kim, W.-S. Kim, H.-C. Kim, B.-S. Lee, H. Kim, W.-R. Yu, K. Kang and S.-H. Hong, Nanoscale, 2013, 5, 8480-8483.

137 G. Ji, B. Ding, Y. Ma and J. Y. Lee, Energy Technol., 2013, 1, 567-572.

138 J.-H. Lee, M.-H. Hon, Y.-W. Chung and I.-C. Leu, Appl. Phys. A, 2011, 102, 545-550.

139 B. Ahmed, M. Shahid, D. H. Nagaraju, D. H. Anjum, M. N. Hedhili and H. N. Alshareef, ACS Appl. Mater. Interfaces, 2015, 7, 13154-13163.

140 Z. Xu, H. Wang, Z. Li, A. Kohandehghan, J. Ding, J. Chen, K. Cui and D. Mitlin, J. Phys. Chem. C, 2014, 118, 1838718396.

141 C.-F. Lin, M. Noked, A. C. Kozen, C. Liu, O. Zhao, K. Gregorczyk, L. Hu, S. B. Lee and G. W. Rubloff, ACS Nano, 2016, 10, 2693-2701.

142 D. Mohanty, J. Li, S. C. Nagpure, D. L. Wood and C. Daniel, MRS Energy \& Sustainability, 2015, 2, E15.

143 D. Mohanty, A. Huq, E. A. Payzant, A. S. Sefat, J. Li, D. P. Abraham, D. L. Wood III and C. Daniel, Chem. Mater., 2013, 25, 4064-4070.

144 D. Mohanty, A. S. Sefat, J. Li, R. A. Meisner, A. J. Rondinone, E. A. Payzant, D. P. Abraham, D. L. Wood III and C. Daniel, Phys. Chem. Chem. Phys., 2013, 15, 19496-19509.

145 X. Zhang, I. Belharouak, L. Li, Y. Lei, J. W. Elam, A. Nie, X. Chen, R. S. Yassar and R. L. Axelbaum, Adv. Energy Mater., 2013, 3, 1299-1307.

146 E. Zhao, X. Liu, H. Zhao, X. Xiao and Z. Hu, Chem. Commun., 2015, 51, 9093-9096.

147 X. Zhang, S. Sun, Q. Wu, N. Wan, D. Pan and Y. Bai, J. Power Sources, 2015, 282, 378-384. 
148 W. Yuan, H. Z. Zhang, Q. Liu, G. R. Li and X. P. Gao, Electrochim. Acta, 2014, 135, 199-207.

149 T. Zhao, S. Chen, R. Chen, L. Li, X. Zhang, M. Xie and F. Wu, ACS Appl. Mater. Interfaces, 2014, 6, 21711-21720.

150 H. Liu, C. Chen, C. Du, X. He, G. Yin, B. Song, P. Zuo, X. Cheng, Y. Ma and Y. Gao, J. Mater. Chem. A, 2015, 3, 2634-2641.

151 J. Liu, B. Reeja-Jayan and A. Manthiram, J. Phys. Chem. C, 2010, 114, 9528-9533.

152 S. K. Martha, J. Nanda, Y. Kim, R. R. Unocic, S. Pannala and N. J. Dudney, J. Mater. Chem. A, 2013, 1, 5587-5595.

153 J. Zhang, Z. Lei, J. Wang, Y. NuLi and J. Yang, ACS Appl. Mater. Interfaces, 2015, 7, 15821-15829.

154 Q. Q. Qiao, H. Z. Zhang, G. R. Li, S. H. Ye, C. W. Wang and X. P. Gao, J. Mater. Chem. A, 2013, 1, 5262-5268.

155 L. Guo, J. Li, T. Cao, H. Wang, N. Zhao, F. He, C. Shi, C. He and E. Liu, ACS Appl. Mater. Interfaces, 2016, 8, 2459424602.

156 H. Z. Zhang, Q. Q. Qiao, G. R. Li, S. H. Ye and X. P. Gao, J. Mater. Chem., 2012, 22, 13104-13109.

157 F. Wu, N. Li, Y. Su, L. Zhang, L. Bao, J. Wang, L. Chen, Y. Zheng, L. Dai, J. Peng and S. Chen, Nano Lett., 2014, 14, 3550-3555.

158 Q. Xia, X. Zhao, M. Xu, Z. Ding, J. Liu, L. Chen, D. G. Ivey and W. Wei, J. Mater. Chem. A, 2015, 3, 3995-4003.

159 S. Chen, Y. Zheng, Y. Lu, Y. Su, L. Bao, N. Li, Y. Li, J. Wang, R. Chen and F. Wu, ACS Appl. Mater. Interfaces, 2017, 9, 8669-8678.

160 R. Alcántara, M. Jaraba, P. Lavela and J. L. Tirado, J. Electroanal. Chem., 2004, 566, 187-192.

161 S. Tao, F. Kong, C. Wu, X. Su, T. Xiang, S. Chen, H. Hou, L. Zhang, Y. Fang, Z. Wang, W. Chu, B. Qian and L. Song, J. Alloys Compd., 2017, 705, 413-419.

162 Y. Fan, J. Wang, Z. Tang, W. He and J. Zhang, Electrochim. Acta, 2007, 52, 3870-3875.

163 B. Ju, X. Wang, C. Wu, Q. Wei, X. Yang, H. Shu and Y. Bai, J. Solid State Electrochem., 2014, 18, 115-123.

164 X. Li, W. Guo, Y. Liu, W. He and Z. Xiao, Electrochim. Acta, 2014, 116, 278-283.

165 J. Wang, S. Yao, W. Lin, B. Wu, X. He, J. Li and J. Zhao, J. Power Sources, 2015, 280, 114-124.

166 X.-W. Gao, Y.-F. Deng, D. Wexler, G.-H. Chen, S.-L. Chou, H.-K. Liu, Z.-C. Shi and J.-Z. Wang, J. Mater. Chem. A, 2015, 3, 404-411.

167 S. Zhao, Y. Bai, Q. Chang, Y. Yang and W. Zhang, Electrochim. Acta, 2013, 108, 727-735.

168 Q. Wu, Y. Yin, S. Sun, X. Zhang, N. Wan and Y. Bai, Electrochim. Acta, 2015, 158, 73-80.

169 J. Y. Shi, C.-W. Yi and K. Kim, J. Power Sources, 2010, 195, 6860-6866.

170 X. Yi, X. Wang, B. Ju, H. Shu, W. Wen, R. Yu, D. Wang and X. Yang, Electrochim. Acta, 2014, 134, 143-149.

171 H. Şahan, M. N. Ateş, F. K. Dokan, A. Ülgen and Ş. Patat, Bull. Mater. Sci., 2015, 38, 141-149.

172 W. Wen, S. Chen, Y. Fu, X. Wang and H. Shu, J. Power Sources, 2015, 274, 219-228.
173 N. Ding, Y. Lum, S. Chen, S. W. Chien, T. S. A. Hor, Z. Liu and Y. Zong, J. Mater. Chem. A, 2015, 3, 1853-1857.

174 Z. W. Seh, H. Wang, N. Liu, G. Zheng, W. Li, H. Yao and Y. Cui, Chem. Sci., 2014, 5, 1396-1400.

175 C. Zhang, H. B. Wu, Z. Guo and X. W. Lou, Electrochem. Commun., 2012, 20, 7-10.

176 T. Takeuchi, H. Sakaebe, H. Kageyama, H. Senoh, T. Sakai and K. Tatsumi, J. Power Sources, 2010, 195, 2928-2934.

177 Z. W. Seh, J. H. Yu, W. Li, P.-C. Hsu, H. Wang, Y. Sun, H. Yao, Q. Zhang and Y. Cui, Nat. Commun., 2014, 5, 5017.

178 R. Tan, J. Yang, J. Hu, K. Wang, Y. Zhao and F. Pan, Chem. Commun., 2016, 52, 986-989.

179 X. Li, Y. Chen, J. Zou, X. Zeng, L. Zhou and H. Huang, J. Power Sources, 2016, 331, 360-365.

180 Y. Zhu, X. Fan, L. Suo, C. Luo, T. Gao and C. Wang, ACS Nano, 2016, 10, 1529-1538.

181 T. B. Schon, B. T. McAllister, P.-F. Li and D. S. Seferos, Chem. Soc. Rev., 2016, 45, 6345-6404.

182 J. Xie and Q. Zhang, J. Mater. Chem. A, 2016, 4, 7091-7106. 183 Y. Liang, Z. Tao and J. Chen, Adv. Energy Mater., 2012, 2, 742-769.

184 W. Huang, Z. Zhu, L. Wang, S. Wang, H. Li, Z. Tao, J. Shi, L. Guan and J. Chen, Angew. Chem., Int. Ed., 2013, 52, 9162-9166.

185 H. Chen, M. Armand, M. Courty, M. Jiang, C. P. Grey, F. Dolhem, J.-M. Tarascon and P. Poizot, J. Am. Chem. Soc., 2009, 131, 8984-8988.

186 X. Dong, H. Yu, Y. Ma, J. L. Bao, D. G. Truhlar, Y. Wang and Y. Xia, Chem.-Eur. J., 2017, 23, 2560-2565.

187 L. Suo, O. Borodin, T. Gao, M. Olguin, J. Ho, X. Fan, C. Luo, C. Wang and K. Xu, Science, 2015, 350, 938-943.

188 R. Chen and R. Hempelmann, Electrochem. Commun., 2016, 70, 56-59.

189 L. Coustan, G. Shul and D. Bélanger, Electrochem. Commun., 2017, 77, 89-92.

190 D. Gordon, M. Y. Wu, A. Ramanujapuram, J. Benson, J. T. Lee, A. Magasinski, N. Nitta, C. Huang and G. Yushin, Adv. Energy Mater., 2015, 6, 1501805.

191 Z. Du, D. L. Wood, C. Daniel, S. Kalnaus and J. Li, J. Appl. Electrochem., 2017, 47, 405-415.

192 K. Xu, Chem. Rev., 2014, 114, 11503-11618.

193 S. Rothermel, P. Meister, G. Schmuelling, O. Fromm, H.-W. Meyer, S. Nowak, M. Winter and T. Placke, Energy Environ. Sci., 2014, 7, 3412-3423.

194 T. Placke, O. Fromm, S. F. Lux, P. Bieker, S. Rothermel, H.-W. Meyer, S. Passerini and M. Winter, J. Electrochem. Soc., 2012, 159, A1755-A1765.

195 J. A. Read, A. V. Cresce, M. H. Ervin and K. Xu, Energy Environ. Sci., 2014, 7, 617-620.

196 K. Beltrop, P. Meister, S. Klein, A. Heckmann, M. Grünebaum, H.-D. Wiemhöfer, M. Winter and T. Placke, Electrochim. Acta, 2016, 209, 44-55.

197 É. Deunf, P. Moreau, É. Quarez, D. Guyomard, F. Dolhem and P. Poizot, J. Mater. Chem. A, 2016, 4, 6131-6139.

198 K. Sakaushi, E. Hosono, G. Nickerl, T. Gemming, H. Zhou, S. Kaskel and J. Eckert, Nat. Commun., 2013, 4, 1485. 
199 L. Zhang, S. X. Dou, H. K. Liu, Y. Huang and X. Hu, Adv. Sci., 2016, 3, 1600115.

200 Y. Zhang, H. Zhao and Y. Du, J. Mater. Chem. A, 2016, 4, 7155-7159.

201 B. L. Ellis, T. N. Ramesh, L. J. M. Davis, G. R. Goward and L. F. Nazar, Chem. Mater., 2011, 23, 5138-5148.

202 C. Masquelier and L. Croguennec, Chem. Rev., 2013, 113, 6552-6591.

203 S.-I. Park, S. Okada and J.-i. Yamaki, J. Novel Carbon Res. Sci., 2011, 3, 27-31.

204 E. Kobayashi, L. S. Plashnitsa, T. Doi, S. Okada and J.-i. Yamaki, Electrochem. Commun., 2010, 12, 894-896.

205 L. S. Plashnitsa, E. Kobayashi, S. Okada and J.-i. Yamaki, Electrochim. Acta, 2011, 56, 1344-1351.

206 V. S. Nair, Y. L. Cheah and S. Madhavi, J. Electrochem. Soc., 2014, 161, A256-A263.

207 S. Guo, H. Yu, P. Liu, Y. Ren, T. Zhang, M. Chen, M. Ishida and H. Zhou, Energy Environ. Sci., 2015, 8, 1237-1244.

208 S. Wang, L. Wang, Z. Zhu, Z. Hu, Q. Zhao and J. Chen, Angew. Chem., Int. Ed., 2014, 53, 5892-5896.

209 Y.-J. Zhang, X.-H. Xia, X.-L. Wang, C.-D. Gu and J.-P. Tu, RSC $A d v .$, 2016, 6, 66161-66168.

210 J.-J. Woo, V. A. Maroni, G. Liu, J. T. Vaughey, D. J. Gosztola, K. Amine and Z. Zhang, J. Electrochem. Soc., 2014, 161, A827-A830.

211 H. Xia, B. Li and L. Lu, RSC Adv., 2014, 4, 11111-11114.

212 L. dos Santos-Gómez, J. M. Compana, S. Bruque, E. R. Losilla and D. Marrero-López, J. Power Sources, 2015, 279, 419-427.

213 R. A. Potash, J. R. McKone, S. Conte and H. D. Abruña, J. Electrochem. Soc., 2016, 163, A338-A344.

214 W. Duan, R. S. Vemuri, J. D. Milshtein, S. Laramie, R. D. Dmello, J. Huang, L. Zhang, D. Hu, M. Vijayakumar, W. Wang, J. Liu, R. M. Darling, L. Thompson, K. Smith, J. S. Moore, F. R. Brushett and X. Wei, J. Mater. Chem. A, 2016, 4, 5448-5456.

215 S. H. Oh, C.-W. Lee, D. H. Chun, J.-D. Jeon, J. Shim, K. H. Shin and J. H. Yang, J. Mater. Chem. A, 2014, 2, 19994-19998.

216 J. Winsberg, C. Stolze, S. Muench, F. Liedl, M. D. Hager and U. S. Schubert, ACS Energy Lett., 2016, 1, 976-980.
217 Q. Huang, H. Li, M. Grätzel and Q. Wang, Phys. Chem. Chem. Phys., 2013, 15, 1793-1797.

218 G. L. Soloveichik, Chem. Rev., 2015, 115, 11533-11558.

219 M. Duduta, B. Ho, V. C. Wood, P. Limthongkul, V. E. Brunini, W. C. Carter and Y.-M. Chiang, Adv. Energy Mater., 2011, 1, 511-516.

220 H. Chen and Y.-C. Lu, Adv. Energy Mater., 2016, 6, 1502183.

221 F. Pan and Q. Wang, Molecules, 2015, 20, 20499-20517.

222 F. Pan, Q. Huang, H. Huang and Q. Wang, Chem. Mater., 2016, 28, 2052-2057.

223 Y. G. Zhu, C. Jia, J. Yang, F. Pan, Q. Huang and Q. Wang, Chem. Commun., 2015, 51, 9451-9454.

224 I. Ruggeri, C. Arbizzani and F. Soavi, Electrochim. Acta, 2016, 206, 291-300.

225 F. Y. Fan, W. H. Woodford, Z. Li, N. Baram, K. C. Smith, A. Helal, G. H. McKinley, W. C. Carter and Y.-M. Chiang, Nano Lett., 2014, 14, 2210-2218.

226 C. Li, A. L. Ward, S. E. Doris, T. A. Pascal, D. Prendergast and B. A. Helms, Nano Lett., 2015, 15, 5724-5729.

227 H. Pan, X. Wei, W. A. Henderson, Y. Shao, J. Chen, P. Bhattacharya, J. Xiao and J. Liu, Adv. Energy Mater., 2015, 5, 1500113.

228 H. Chen, Q. Zou, Z. Liang, H. Liu, Q. Li and Y.-C. Lu, Nat. Commun., 2015, 6, 5877.

229 M. L. Perry and A. Z. Weber, J. Electrochem. Soc., 2016, 163, A5064-A5067.

230 Y. Shao, Y. Cheng, W. Duan, W. Wang, Y. Lin, Y. Wang and J. Liu, ACS Catal., 2015, 5, 7288-7298.

231 R. Dmello, J. D. Milshtein, F. R. Brushett and K. C. Smith, J. Power Sources, 2016, 330, 261-272.

232 R. Chen, S. Kim and Z. Chang, Redox Flow Batteries: Fundamentals and Applications, Redox: Principles and Advance Applications, ed. M. A. A. Khalid, Publisher: InTech, 2017, ISBN 978-953-51-5421-1.

233 X. Li, H. Zhang, Z. Mai, H. Zhang and I. Vankelecom, Energy Environ. Sci., 2011, 4, 1147-1160.

234 J. R. Varcoe, P. Atanassov, D. R. Dekel, A. M. Herring, M. A. Hickner, P. A. Kohl, A. R. Kucernak, W. E. Mustain, K. Nijmeijer, K. Scott, T. Xu and L. Zhang, Energy Environ. Sci., 2014, 7, 3135-3191. 